\title{
Violence Against Women amid COVID-19: The Effects of Social and Traditional Media Campaigns to Empower Women* Pre-Analysis Plan
}

\author{
Fotini Christia, Horacio Larreguy, Norhan Muhab, Elizabeth Parker-Magyar
}

April 1, 2021

\section{Abstract}

Systematic reviews of violence against women in the Arab world highlight the high prevalence of gender based and intimate partner violence (GBV and IPV) alongside the need for more research to inform prevention and response. Women's exposure to GBV and IPV may be especially acute amid COVID-19, which has led to a notable increase in reported violence, particularly in the Global South. Building on recent studies on the role of edutainment and community-level interventions in combatting GBV and IPV, we partnered with an Egyptian women's rights non-governmental organization to examine an intervention delivered amid COVID-19 via traditional and social media that are widely used in the Egyptian context. We measure the degree to which the intervention shifts attitudes toward GBV and IPV, knowledge about resources, and behaviors in response.

${ }^{*}$ This project has received approval from MIT's Committee on the Use of Humans as Experimental Subjects (COUHES) 2006000174 and from the American University of Cairo (AUC) Institutional Review Board 2020-2021-003. Abeer El-Kayaty and John Marshall provided useful feedback. Zainab Asal, Hadeer Hegazy, and Shahd Eid provided excellent research assistance. 


\section{Introduction}

As a result of emergency response measures and pandemic-induced restrictions of movement, along with the associated economic and social stress, women across the globe have been at heightened risk for gender-based violence (GBV) and intimate partner violence (IPV), ${ }^{1}$ particularly in the Global South. ${ }^{2}$ The social distancing and quarantine measures have also increased the need for online ways to disseminate information on risks and services, as well as to offer support. Harnessing the increased use of social media during the pandemic, we have set out to conduct an impact evaluation of the "You Are Not Alone" social media campaign against GBV and IPV in Egypt, as well as assess the effect of a traditional TV campaign on the these issues. Specifically, we partnered with an established women's rights organization to evaluate the dissemination of video messages and information about ongoing television programming to approximately 6,000 WhatsApp and Facebook subscribers as part of an information campaign against GBV and IPV aimed at ensuring affected women get access to information resources and services to cope with their situation.

Beyond being morally reprehensible, GBV and IPV increase social inequality and undermine economic development. The prevalence of GBV and IPV across the globe and the significant economic costs associated with it (Krug et al. (2002)) have led to an increase in research on how to curb it. Both forms of violence are often driven by inequities in relationships, lack of respect for gender norms, tolerance toward violence against women, and unequal access to supportive resources. Recent systematic reviews have looked at the role of men's attitudes toward intimate partner violence (McCarthy et al. (2018)); intimate partner violence during pregnancy (Shamu et al. (2013); Alebel et al. (2018); Wang et al. (2017)); and intimate partner violence and HIV infection (Osinde et al. (2011); Li et al. (2014); Phillips et al. (2014).

Though the first wave of scholarship focused on the Global North, there has been a deliberate shift towards low- and middle-income countries (Guedes et al. (2016)) with systematic reviews examining so-called structural interventions (Bourey et al. (2015)) ${ }^{3}$ and psychological interventions (Keynejad et al. (2020)) to curb IPV; primary healthcare interventions within public health systems to address IPV (Signorelli et al. (2018)); as well as prevention of GBV in adolescent girls (Lundgren and Amin (2015); Yount et al. (2017)). The main findings highlight the need to address traditional gender norms, integrate services to prevent violence against women (Semahegn et al. (2019)), improve access to support centers (Kirk et al. (2017)) and consider community-based interventions including public engagement and advocacy (Lundgren and Amin (2015)).

\footnotetext{
1 "Impact Report: COVID-19 and Domestic Violence Trends," National Commission on COVID-19 and Criminal Justice, February 23, 2021, Link.

${ }^{2}$ Rivera et. al, "What does coronavirus mean for women?", United Nations Development Programme, July 13, 2020, Link; "Gendered Impact of Covid-19 Outbreaks in Development and Humanitarian Settings," CARE, March 16, 2020, Link.

${ }^{3}$ Defined as those aiming to change "aspects of the economic, politico-legal, physical and social environment that produce and reproduce risk" ((Bourey et al., 2015, 2)).
} 
There remains a dearth of work on violence against women in the Arab world as highlighted by two recent systematic reviews (Hawcroft et al. (2019); Elghossain et al. (2019)) calling for more work to inform prevention and response to GBV and IPV in the Middle East and North Africa (MENA) region. Heightened inequality and social barriers for women in the Arab world translate into a public health problem with notable levels of physical and psychological intimate partner violence (Elghossain et al. (2019)) and needs expedient attention particularly given the pandemic. Informational or edutainment interventions around GBV and IPV have been conducted in other contexts (Green et al. (2019), Cooper et al. (2020), Arias (2019), Banerjee et al. (2019)). But like similar interventions focused on corruption (Blair et al. (2019)) or deference to authority (Paluck and Green (2009)), the findings from these informational interventions have been mixed and the mechanisms through which shifts occur remain underspecified. Moreover, there is the question of whether previous edutainment interventions requiring substantial resources can be scaled up by exploiting traditional and social media.

We partnered with an established women's rights NGO to distribute a series of videos related to women's empowerment, GBV, and IPV, as well as reminders about a similar, ongoing television campaign. After conducting a baseline survey of 5,818 Egyptian women in June-July 2020, we randomly assigned respondents to these treatment conditions via the two most popular social media platforms in Egypt: via WhatsApp, individually and within groups, and via Facebook message. ${ }^{4}$ Our fully online design enabled the selection of an all-female sample. In addition to allowing a close focus on women's attitudes toward a very important phenomenon affecting women in Egypt and MENA more broadly, this sample had two practical benefits. First, our NGO partner that created these videos designs content specifically for women. Second, these issues can be taboo in mixed-gender discussions. As some of our treatment content was disseminated via groups, rather than individually, we wanted to avert the potential for harassment of women online that could occur in mixedgender groups.

Despite these social media platforms wide use in Egypt (Newman et al. (2019)) as elsewhere, a first challenge of our study was whether individuals would watch and consume the information we delivered via these platforms, given their limited attention and the significant amount of information and notifications they receive online. While scholars have used WhatsApp and Facebook to examine phenomena like misinformation (Melo et al. (2019); Badrinathan (2020); Bowles et al. (2020)) and political accountability (Enríquez et al. (2019)), we are not aware of any study that probes the suitability of Facebook and WhatsApp in edutainment interventions.

In an endline survey conducted in September-October 2020, we measure the degree to which those receiving treatment shifted their attitudes towards GBV and IPV, their knowledge of women's legal rights and resources, their hypothetical behaviors in responding to GBV or IPV, and their revealed preferences over addressing GBV and IPV via their willingness to donate to NGOs working on tackling such violence. Subject to the effectiveness of

\footnotetext{
${ }^{4}$ There were 38 million Facebook and 24 million WhatsApp users in Egypt as of January 2020. "Data Reportal", Link.
} 
the mode of dissemination, we expect our intervention to be successful at getting individuals to consume the intervention information, given our partner's high status and the wide use of social media platforms in Egypt, and for the intervention to provoke shifts in attitude, knowledge, and some behaviors.

Our intervention is intended to make three contributions. First, it examines the effect of social and traditional media interventions not only seeking an attitudinal change but also providing information about resources, something increasingly relevant in curbing GBV and IPV, and even more salient in the COVID-19 environment. Second, it examines both the relative effectiveness of traditional and social media, and that of different social media platforms through which information is disseminated, as well as whether it is disseminated individually or via groups. This will render the findings relevant and transportable to those considering informational interventions in other areas that are relevant to gender rights as well as public health. Finally, it focuses on women's attitudes and behaviors in Egypt, a central country in the Arab world and an influencer in the MENA region.

\section{Literature Review}

Women are often socialized to accept GBV and IPV despite its status as a serious public health problem and human rights violation with deleterious impacts on economic development (Krug et al. (2002)). A recent meta-analysis of research in public and reproductive health on GBV and IPV prevalence in low-and-middle income countries emphasizes the need to shift norms and attitudes about the justifiability of violence and gender equality, while empowering women and integrating services (Semahegn et al. (2019)). In addition to norms justifying violence (Pierotti (2013); Messing and Thaller (2015); Arias (2019)), researchers also identify a lack of knowledge of legal rights and resources and fears of social sanctioning as limiting women's willingness to report or respond to violence (Cooper et al. (2020)).

In-person community level "mobilization" interventions (Abramsky et al. (2014, 2016); Wagman et al. (2015); Sharma et al. (2020)) provide useful insights into the role that communal attitudes play in sustaining high levels of GBV and IPV prevalence. Through engagement of stakeholders in critical conversations on gender equity, these interventions have found success in shifting attitudes toward efficacy, empowerment, and norms around reporting, but are expensive, difficult to replicate across contexts, and infeasible amid COVID-19. Our intervention builds on these insights to examine the effectiveness of a television show and social media campaign that aims to shift attitudes while providing women with information about available services and their legal rights surrounding GBV and IPV. Conducted during the early months of the COVID-19 pandemic, which exacerbated global risk factors for GBV and IPV (Peterman et al. (2020)) and increased reliance on social and traditional

media for information, the intervention explores when and through what mechanisms media can shift attitudes and behaviors related to GBV and IPV in a more cost-effective way than more resource-intensive mobilization interventions. 
One branch of research suggests that media impacts attitudes and behaviors not through persuasion (DellaVigna and Gentzkow, 2010) but through communal transmission, which can provoke shifts in beliefs about social norms (Chwe, 1998). Testing these two different channels, Arias (2019) finds support for the role of communal transmission, showing that such programming on GBV in a Mexican community increased rejection of violence against women and support for gender equality, while individually transmitted information had no impact. ${ }^{5}$ Outside of GBV and IPV, recent explanations for mixed findings in information interventions around subjects like electoral accountability (Dunning et al. (2019), Adida et al. (2020), Boas et al. (2019), Humphreys and Weinstein (2012)) also posit that the share of a community that is targeted with information can drive discussion and coordination (Enríquez et al. (2019), Alatas et al. (2016), Banerjee et al. (2011), Ferraz and Finan (2008), Larreguy et al. (2020), Marshall (2019)). Like these phenomena, GBV or IPV is a communal level norm or issue as individuals who are aware of or reject a phenomenon may be unlikely to take action unless they believe others will do so. As a result, public and wide-reaching information may be needed to generate discussion and coordination among community members (Enríquez et al. (2019)).

Research on "edutainment," meanwhile, suggests messaging from role models or highly entertaining content can also cue shifts in norms perceptions, without necessarily requiring high levels of information targeting or communal transmission (Tankard and Paluck (2016); Singhal and Rogers (2012)). A focus on content can account for seemingly divergent findings linking media to attitudes, for instance that the introduction of cable television in some places drove substantial shifts in gender attitudes (Jensen and Oster, 2009; La Ferrara et al., 2012) even as non-fictionalized, media interventions around other public health concerns have had relatively small effects (Galiani et al. (2012)). Experimental edutainment interventions have lowered deference to authorities in Rwanda (Paluck and Green (2009)) and increased reporting of corruption in Nigeria (Blair et al. (2019)), but had mixed results in encouraging the poor in India to participate in an anti-poverty scheme (Ravallion et al. (2015)).

Applying an edutainment approach to GBV, Green et al. (2019) find that a communallytransmitted edutainment intervention in Uganda did not shift attitudes about the legitimacy of violence against women but increased hypothetical willingness to report to authorities via reduced fears of social sanctioning around reporting (Cooper et al. (2020)). ${ }^{6}$ In a separate edutainment study, Banerjee et al. (2019) find that manipulating the content of a TV series in Nigeria shifts the attitudes of respondents toward domestic violence, identifying effects

\footnotetext{
${ }^{5}$ Arias also finds that the intervention increased pessimism of whether violence would decline in the future. He posits the mechanism for this surprising finding is that the intervention provided no information on channels to report or respond to GBV or IPV. Our intervention provides these channels, so we expect different outcomes.

${ }^{6}$ In doing so, the authors point to the role social desirability bias - in the form of fear of social sanctioning - plays in limiting reporting and sustaining violence. Even women who believe violence is unacceptable may be hesitant to disclose their status as survivors of GBV and IPV if they believe they will face social repercussions. While we think it is unlikely that our survey measures are subject to this concern since they were conducted privately, as explained in detail later, our survey instrument was designed to test the extent of social desirability bias in reporting.
} 
among those who better recall the show and its characters (Banerjee et al. (2019), p. 133). These studies suggest that information from high-status or fictionalized characters may have the power to shape perceptions of communal norms - with Green et al. (2019) placing deeper emphasis on perceptions of communal level beliefs, and Banerjee et al. (2019) examining more diffuse perceptions about a broader culture.

Another branch of interventions to combat GBV and IPV focuses on women's access to financial resources, linking women's economic and social empowerment to reductions in violence. Studies in South Africa (Kim et al. (2007)), Ecuador (Hidrobo and Fernald (2013)) and elsewhere find that increasing access to women's financial resources improves outcomes related to GBV and IPV, likely via their economic and social empowerment (Field et al. (2019)). While meta-analyses have found broadly consistent links (Bourey et al. (2015)), one recent evaluation of a program in Peru found that experimentally granting women access to savings funds had no impact on most social and health outcomes (Tankard and Paluck (2016)). These studies suggest that women's financial and employment status may drive heterogeneity in their responses to media. As COVID-19 has likely led to substantial income and employment loss, it is likely that women in our study are more vulnerable to GBV and IPV than prior to the pandemic. Other systematic studies link educational attainment to GBV exposure, though a recent systematic review of GBV in the Arab world noted that high levels of educational attainment for women had yet to translate into economic empowerment or "shifting domestic power dynamics" (Hawcroft et al., 2019).

Our study takes place against the backdrop of COVID-19, which likely exacerbates women's exposure to GBV and IPV. Already, researchers have documented increased reporting of domestic violence via calls to hotlines or formal authorities in contexts as diverse as India (Ravindran and Shah, 2020), Peru (Agüero, 2020), and the United States (Boserup et al., 2020). Peterman et al. (2020) outline diverse pathways for pandemics to increase violence against women, including through economic stress, social isolation, conflict and instability, increased exposure to troubling relationships, reducing "health service availability and access to first responders," and limiting women's ability to "escape abusive partners" (Peterman et al. (2020), p. 1). This research suggests that there may be heterogeneous effects among those who have experienced severe disruptions due to COVID-19, like loss of income, overcrowding in the home, or a partner's return from work overseas.

\subsection{Theory of Change}

As a first stage measurement, we expect treated individuals to receive and watch the video content we distributed via WhatsApp and Facebook messages to those in the corresponding treatment arms. Similarly, we expect those assigned the television show reminders to recall them and to watch the show. Unlike interventions featuring community screenings (Banerjee et al. (2019); Blair et al. (2019); Green et al. (2019), we deliver content individually and in groups into individuals' homes via their phones or computers. Similar to soap operas (Jensen and Oster (2009), La Ferrara et al. (2012)) and serialized interventions that 
drove attitudinal effects (Banerjee et al. (2019); Paluck and Green (2009)), and unlike those featuring content delivered in a single day (Green et al. (2019); Arias (2019)), this method of delivery allowed us to distribute or encourage the viewing of content at regular intervals over a sustained period of time. Given the centrality of WhatsApp and Facebook as social media and messaging platforms, our first prediction is that these platforms are effective at delivering the intervention content and thus treated respondents at endline should report receiving the Facebook and WhatsApp messages, the TV show reminders, and watching some of the content delivered, or nudged to watch for the case of the TV show.

- Hypothesis 1 : Individuals targeted with content delivered via WhatsApp and Facebook message will be more likely to report viewing it and accurately recall its content.

- Hypothesis 2 : Individuals who receive reminders to watch the television show will be more likely to report viewing it and accurately recall its content.

- Hypothesis 3 : Individuals who are sent intervention content via WhatsApp groups will more accurately recall the content than those who receive the content via individual message, especially if groups engage in discussion around the content delivered.

Next, we focus on shifts in attitudes, knowledge, and behaviors across the topics addressed in our intervention, including domestic violence, sexual assault or harassment and female empowerment or future outlook. ${ }^{7}$

Among those for whom social media is a successful model of information delivery, we expect our intervention to shift attitudes about gender norms and increase rejection of violence against women. Our intervention should shift these outcomes because it features a high status figure who leads a prominent women's rights organization sharing viewpoints and knowledge on these topics in a conversational and engaging tone to a country-wide mostly female audience. Nehad Aboul Komsan's popularity likely cues similar norms perceptions as in edutainment interventions (Banerjee et al. (2019), Paluck and Green (2009)) where high-status figures or dramatized events can capture individuals' attention, and model, inspire, and motivate shifts in social behaviors (Singhal and Rogers (2012), Bandura (2002)). While our intervention features no fictionalization, Aboul Komsan aligns with Bandura's description of a "culturally admired" figure whose social attractiveness "increases the impact of modeling behaviors" (Bandura (2003), p. 83). This status and the content of information leads us to our second prediction, that individuals who received and viewed the video messages will change their attitudes toward gender norms, increasing their rejection of violence against women.

- Hypothesis 4 : Treated individuals will shift their attitudes about gender norms and increasingly reject violence against women, relative to those in control.

\footnotetext{
${ }^{7}$ We discuss our measurement of these variables in the Empirical Framework section.
} 
The treatment arms that entailed the communal distribution of videos through WhatsApp groups and nudges to watch the TV show resemble those interventions exploring communal media in the context of GBV and IPV (Arias (2019)) and those focused on information and accountability (Enríquez et al. (2019), Alatas et al. (2016), Ferraz and Finan (2008), Marshall (2019), Banerjee et al. (2011)) that feature a high share of individuals treated within a community and thus had the potential to spur discussion and explicit coordinated behavior. In reaching broad populations, in principle, information about GBV and IPV disseminated to a large number of individuals can also constitute a signal that triggers tacit coordination spurring shifts in attitudes and behavior (Morris and Shin (2002)) supporting women's empowerment and rejecting violence against women. However, given that the control group was also recruited via Facebook ads and that we did not reach such a large number of study participants, we do not believe we necessarily cued this effect differentially among treated individuals. Even in the absence of the latter coordinating effects, information about GBV and IPV, may shift attitudes supporting women's empowerment and rejecting violence against women. This should in principle occur regardless of treatment dissemination channel, though we may expect stronger impacts among those who receive information communally via groups, especially when it ignited discussion, or via TV, as collectively transmitted media can generate common knowledge that facilitates norm change (Chwe (1998)).

- Hypothesis 5 Treated individuals who receive the treatment information via collective channels such as WhatsApp group or TV show will exhibit stronger attitudinal changes, compared with those receiving the video messages individually, if these induce enough discussion and explicit or tacit coordination. ${ }^{8}$

We further predict that our intervention will increase optimism about women's equality and empowerment in the future. Optimism is closely related to present attitudes: In Appendix Tables 16 and 17 we see that those rejecting violence and in favor of greater gender equality at baseline hold more optimistic outlooks toward gender equality moving forward. While Arias (2019) finds that his intervention increases pessimism about the future, our intervention strongly emphasizes resources available to those combating GBV and IPV, seeks to destigmatize them and underlines the social importance of accessing those resources.

- Hypothesis 6 : Treated individuals will express increased optimism about women's equality and empowerment in the future, relative to those in the control group.

We also predict that the intervention will increase knowledge of resources, as well as hypothetical and observed behaviors around supporting victims of violence.Our knowledgebased questions focus on online resources and organizations supporting women affected by

\footnotetext{
${ }^{8}$ Note that, while we can measure discussions within WhatsApp groups, it was not possible to measure common knowledge, and thus test this specific mechanism behind potentially larger reduced form effects on attitudes of information distributed via collective channels.
} 
domestic violence, sexual harassment, or assault. Those treated should be more knowledgeable about resources available to women than at baseline.

- Hypothesis 7 : Individuals who receive the intervention via social media or on TV will exhibit increased knowledge about GBV- and IPV-related resources for women.

Hypothetical and observed behaviors should move in tandem with attitudes and knowledge about resources, given their high degree of correlation at baseline. We measure hypothetical behavior through a series of scenarios in which a friend or acquaintance has faced domestic violence or sexual assault, which ask how likely an individual would be to address the situation internally (seek a solution with her husband or via her family, seek help from an organization or online resources, or report to authorities). We measured observed behavior asking whether they have accessed online resources and contacted an organization that supports and advises women. Existing research (Sable et al., 2006, 157) identifies deep barriers to reporting sexual violence such as fear and guilt, "concerns about confidentiality," and "fear of not being believed"; Green et al. (2019) and Cooper et al. (2020) similarly underscore how fears of social sanctioning limit willingness to report violence. As a result, and due to the nature of the intervention, while we expect recommendations and willingness to report violence to move with attitudes, we anticipate differential effects according to response type.

Though these fears are prevalent in our context, the intervention content speaks to them through emphasizing the importance of believing victims, destigmatizing exposure to violence, and advertising local, non-governmental organizations and resources available to women, including a confidential hotline. As such, we may expect a shift in recommendations and willingness to report violence particularly to these sources emphasized in our treatment content. ${ }^{910}$

- Hypothesis 8 : Treated individuals will be more likely to recommend looking for online resources or contacting a local organization when faced with a hypothetical scenario where a friend or family member faces domestic violence or sexual harassment. ${ }^{11}$ Treated individuals should be more likely to report that they themselves looked for online resources and contacted local organizations that support women.

\footnotetext{
${ }^{9}$ While the intervention content does speak directly to women's legal rights, we do not anticipate a substantive shift in hypothetical reporting to authorities given that our intervention is unlikely to meaningfully address trust in the Egyptian legal system. Moreover the intervention content does not emphasize other responses we measure in the scenario, like confronting a husband or seeking mediation through a local community member, and thus we do not anticipate treatment effects on related outcomes.

${ }^{10}$ At baseline, we see in Appendix Tables 26, 27, and 28 show that individuals who hold views more in favor of gender equality are more likely to look for supportive resources and contact a supportive organization in a hypothetical scenario where a friend tells them they have been affected by domestic violence.

${ }^{11}$ While we also measure whether they would hypothetically contact family members and authorities, we do not expect our treatment to significantly affect such hypothetical outcomes.
} 
We also quantify changes in attitudes, knowledge and observed behavior through revealed preferences in the use of their survey compensation as donation to an NGO supporting women's empowerment in Egypt as a measure of preference for these issues.

- Hypothesis 9 : Treated individuals will be more likely to donate at least part of their survey compensation to an NGO supporting women's empowerment in Egypt.

\subsubsection{Heterogeneous Effects}

We predict that treatment effects on knowledge about resources and attitudinal shifts will be respectively concentrated among those with lower knowledge levels and attitudes more tolerant of violence and less supportive of gender equality at baseline. This is because we expect ceiling effects for individuals who at baseline exhibit high levels of knowledge and attitudes similar to the content delivered in the campaign; where there is little difference between their expressed attitudes and those our partner communicates, there is little reason to believe the intervention should have any impact on attitudes.

Since these baseline variables are endogenous, we will additionally consider heterogeneous effects by their predicted values. To that end, we will use different strategies to project their values onto age, (if applicable) age differential with partner, social (including marital) status, (if applicable) how long married, own and (if applicable) partner's educational attainment, and experiencing severe disruptions due to COVID-19, like loss of income, (if applicable) working with partner from home and a crowded household.

\section{Research Design}

\subsection{Context of GBV in Egypt during COVID-19}

Egypt, one of the most populated countries in MENA with 47.5 million women, has made some notable progress towards gender equality in recent decades. Despite this progress, social and economic inequalities persist and are amply manifested in low female labor force participation, discriminatory cultural norms and gender based violence. ${ }^{12}$ Egypt ranks 134th out of 153 countries in the 2020 Global Gender Gap Index. According to the ILO, female labor force participation is less than $25 \%,{ }^{13}$ and it is not uncommon for women to face discrimination from employers in hiring and pay. ${ }^{14}$

\footnotetext{
${ }^{12}$ World Economic Forum. (2020) "Global Gender Gap Report 2020". Link

${ }^{13}$ World Bank, Link

14 "Women's Participation in Paid Employment in Egypt is a Matter of Policy not Simply Ideology", El Nisaa, July 2019, Link
} 
Furthermore, many forms of gender based violence continue to be a pressing issue that has been gaining increased public attention. A recent poll from the Egyptian Center for Public Opinion Research finds that 11\% of women report having experienced intimate partner violence in the form of being hit, pushed or insulted by their husbands. ${ }^{15}$ According to the 2014 Egypt Demographic and Health Survey, 36\% of ever married women aged 15-49 have experienced physical domestic violence, and in $64 \%$ of these cases the husband was the perpetrator. ${ }^{16}$ Similarly, the Arab Barometer 2019 survey reports $72 \%$ of Egyptian families report a woman in their family experiencing domestic violence in the past 12 months. Further, past descriptive research has shown that more than fifty percent of Egyptians believe domestic violence is justified in some cases (Yount and Li (2009)). Researchers found that women's standard of living, socioeconomic dependence, and relative education levels, ${ }^{17}$ compared to their husbands, were highly predictive of their exposure to domestic violence (Yount and Li (2010)). Despite this high prevalence, domestic violence is not criminalized in Egypt. ${ }^{18}$

In addition to intimate partner violence, sexual harassment in public spaces like streets, schools, and workplaces is also highly prevelant. A study by UN Women finds that 99.3\% of women have experienced one form of harassment or another. ${ }^{19}$ Sexual harassment was officially criminalized in $2014,{ }^{20}$ yet victim blaming continues to be embedded in the culture. ${ }^{21}$ According to the 2019 Arab Barometer report, Egyptians report the highest rates of verbal and physical sexual harassment in the Arab world. $63 \%$ of women, and $90 \%$ of those between the ages of 17 and 28, reported being harassed often, sometimes, or rarely in the past 12 months, with relatively similar numbers between urban and rural areas. In a recent survey by UN women, more women than men blamed the victims for getting harassed. ${ }^{22}$

Gender based violence in the form of female genital mutilation (FGM) is widely practiced in Egypt despite being banned by law. 92\% of married women between the ages of 15-49 reported having undergone FGC, according to the 2014 Egypt Demographic and Health Survey. ${ }^{23}$ FGM was criminalized in $2008,{ }^{24}$ yet the practice is not only prevalent, but support for it continues from both males and females. $70 \%$ of males and $56 \%$ of women approved of the practice, the most common reasons behind such approval being cultural traditions and misperceived religious obligations. ${ }^{25}$ Researchers have emphasized that the

\footnotetext{
15 "Women and Covid-19 Pandemic," UN Women, May 2020, Link

${ }^{16}$ Ministry of Health and Population [Egypt], El-Zanaty and Associates [Egypt], and ICF International. 2015. "Egypt Demographic and Health Survey 2014: Key Findings." Cairo, Egypt and Rockville, Maryland, USA: Ministry of Health and Population and ICF International. Link

${ }^{17}$ This was measured as at least 6 more or fewer years of schooling than a husband

18 "Egypt Gender Justice \& The Law," UNDP, 2018, Link

19 "Study on Ways and Methods to Eliminate Sexual Harassment in Egypt," UN Women, 2013, p. 6, Link

20 "Egypt Gender Justice \& The Law," UNDP, 2018. Link.

21 "Al Azhar Encourages Victims of Assault to Speak Up, Report," Egyptian Streets, July 2020, Link.

22 "Understanding Masculinities: Results from the International Men and Gender Equality Survey - Middle East and North Africa," 42. Link

23 "Female Genital Mutilation," UNFPA, 2020, Link

${ }^{24}$ Ibid.

25 "Understanding Masculinities: Results from the International Men and Gender Equality Survey - Middle East and North Africa," 78. Link.
} 
experience of FGM in childhood increases the odds of subsequently experiencing domestic violence - even as they found little support for the hypothesis that gender stratification or norms about women's family roles predicted experiencing violence (Yount et al. (2020)). However, subsequent research on FGM prevalence found that community norms opposing the practice led to substantive, direct declines; the research called for an intergrative approach addressing both gender norms and structural opportunities (Yount et al. (2020)).

As is the case globally, the COVID-19 pandemic has put Egyptian women at greater risk: women in the Middle East and North Africa have faced high job losses, lost access to social protection, and are reporting higher rates of domestic violence. ${ }^{26}$ Nehad Aboul Komsan's organization has reported that family conflicts and cases of violence reports have increased during the COVID-19 pandemic, making up to $43 \%$ of total cases received by the Gender and Legal Expert House (GELEH). ${ }^{27,28}$

Our intervention takes place amid an outpouring of activism in Egypt around issues of gender equality and violence amid COVID-19. In early July, a high-profile allegation of serial rape at an elite university captivated national media, generating intense focus on the subject across national and social media. It even generated international attention, with references to Egypt having its "Me Too" moment. ${ }^{29}$ That case sparked additional revelations, and a social media-driven movement centered around a hashtag, "End the Silence," sought to "create structural change" by breaking through existing norms that cast blame on women who experience violence, encourage parents to support children reporting assault, insist that formal authorities prosecute abusers, and hold powerful institutions to account. ${ }^{30}$ In response to this campaign, the Egyptian cabinet approved a draft law that protects the identities of sexual assault victims. ${ }^{31}$ Keeping these identities confidential is expected to increase reporting of sexual harassment cases where women would no longer be afraid of harming their reputation in a conservative society that still shames sexual harassment victims. ${ }^{32}$ Our intervention occurs in this climate, where women continue to come forward and multiple prominent cases are in court, even as women continue to face powerful barriers against doing so.

\footnotetext{
26 "ESCWA partners warn: violence against women has increased due to COVID-19; Women will lose twice as much as men in terms of jobs", United Nations Economic and Social Commission for Western Asia, April 6, 2020, Link

27 "Egypt's Hidden Pandemic: Domestic Violence On The Rise During COVID-19," Egyptian Streets, May 2020, Link.

${ }^{28}$ Aseel Alayli, "Domestic Violence and Arab Women's False Choice during COVID-19", The Arab Barometer, June 1, 2020, Link.

${ }^{29}$ Declan Walsh, "Accusations of Serial Rape Push Egypt Toward a Reckoning", The New York Times, July 8, 2020, Link

${ }^{30}$ Sudarsan Raghavan, "Egypt's women are rising up against sexual violence. Others are still being jailed for TikToks.", The Washington Post, July 31, 2020, Link

31 "Egypt Cabinet Approves Bill to Keep Identities of Sexual Assault Victims Confidential," Ahram Online, July 8, 2020, Link.

${ }^{32}$ Ibid.
} 


\subsection{Intervention}

In the context of the COVID-19 pandemic in Egypt, we partnered with an established women's rights organization - the Egyptian Center for Women's Rights (ECWR) - to evaluate the dissemination of video messages, as well as information about ongoing television programming, to approximately 6,000 WhatsApp and Facebook female subscribers as part of an ECWR media campaign against GBV and IPV aimed at ensuring affected women get access to information on resources that help them shape attitudes, knowledge and behavior around these issues. We collected an online panel survey of a large sample of women across Egypt by reaching out to respondents through Facebook, and randomly delivered reminders of television programming and video messages with content via WhatsApp and Facebook. We will examine how random assignment to these messages affects individuals' knowledge, perceptions, and behavior. Specifically, we will measure attitudes toward GBV and IPV and women's empowerment, knowledge of available resources and services to deal with violence, hypothetical behavior in scenarios of exposure to violence, and individuals reported use of such services. In addition to these reported attitudes and behaviors, we will measure observed behaviors and revealed preferences.

Even before the restrictions on freedom of movement associated with COVID-19, social media platforms had become a central source of information for individuals in the Global South due to high internet penetration and associated low cost (Newman et al. (2019)). Egyptians rely heavily on WhatsApp to access and share information thanks to the anonymity it affords. Out of internet users aged 16-64 in Egypt, 68\% are subscribed to WhatsApp. Moreover, Egyptians are also avid Facebook users, with $80 \%$ of the internet users being subscribed to Facebook. ${ }^{33}$. In using social media to deliver messages and reminders about traditional media, this research will contribute to a small body of research on social media in the context of GBV and harassment. This research has largely focused on social media as a site of harassment (Suzor et al. (2019)) - though in the Egyptian context, as discussed above, we focus on social media as a tool for building knowledge, as well as shifting attitudes and behaviors.

Our partner, the Egyptian Center for Women's Rights, is an established, independent, non-partisan non-governmental organization (NGO). Led by founder Nehad Aboul Komsan, they focus on raising awareness and shifting attitudes toward issues facing Egyptian women. The group has a legal focus, and also hosts a hotline for women focused on legal support and awareness. The NGO views WhatsApp, Facebook, and other platforms as an important, underutilized tool for NGOs and public health to disseminate information. Through their current social media presence and television shows, our partner shares perspective and information on issues affecting Egyptian women. They had posted short videos on the organization's Facebook accounts that within months reached 5 million video views and received 3 million reactions - indicating high levels of responsiveness to these videos. As ECWR emphasizes, NGOs and public health practitioners can better use social media in addition to traditional media to disseminate information that aids those facing GBV,

\footnotetext{
${ }^{33}$ StatCounter: Social Media States Egypt, Link
} 
especially given its low cost in comparison to community-wide interventions or even public film screenings. Our intervention will analyze the relative effectiveness of the similar information disseminated in different ways across these platforms. Moving forward, our partner and others can use this information to tailor their messaging strategies most effectively. As anticipated, the intervention targeted an all female sample for a few reasons: The content that ECWR creates is geared toward consumption by a female audience, especially given the current climate of female activism around gender norms and violence in Egypt. Nehad Aboul Komsan, is an established figure among women in Egypt and has a large female following. Further, our partners felt that the "WhatsApp Group" treatment we designed was more appropriate for women-only groups given the risk that women might be harassed on the WhatsApp Groups set up for the intervention.

\subsection{Recruitment, Sampling and Treatment Assignment}

We carried out a baseline survey on a large sample of women across Egypt recruited through Facebook advertisements (5,734 of final sample) and ECWR's social media channels (181 of final sample) from June 18 through July 10, 2020. Given in-person enumeration challenges associated with COVID-19, we did the baseline data collection via an online survey compatible with web and mobile devices. 10,823 completed the survey. Survey respondents were incentivized with a 25 EGP (1.59 USD) mobile phone credit for survey completion. To avoid recruiting the same subjects as are already highly familiar with our partner's content, we built a separate Facebook page titled "Inti Mish Lwa7dek" (You are Not Alone). We targeted advertisements across Egypt boosting a Qualtrics link we posted on the page. Our partner posted welcome videos on the page, explaining the purpose of the project, which received approximately four thousand likes and comments and was shared by hundreds. The advertisements and welcome messages were widely shared, with encouraging comments like, "The idea behind the survey is really nice, I am very proud of you and wish you the best of luck." Figure 2 depicts a screenshot of a welcome video and comments as it appeared on Facebook, which received over 1,200 likes and 170 comments. In 151 total advertisements, Facebook's analytics reported a total of 943,894 views and 96,791 "engagements" (likes, comments, and shares). Figure 1 and Appendix Table 36 use IP address data at the governorate level to show that our baseline survey features respondents from 24 of Egypt's 27 governorates as it oversamples Cairo, where more than half of respondents are from.

As part of the baseline survey, respondents were given the option to add our WhatsApp account to their contacts and to send a message to our Facebook accounts. As a result, we were able to subsequently reach out to enroll respondents in the treatment via those WhatsApp and Facebook accounts without being identified as SPAM and blocked by WhatsApp and Facebook. In line with estimates from previous projects by J-PAL in the region of approximately $60 \%$ enrollment and after removing duplicate responses, which indicated no genuine interest in the intervention, we enrolled 5,828 in one of five treatment conditions. Of these 5,828, 227 responded twice to the endline, and so were excluded from our analysis, leaving us with a final set of 5,618 respondents. The median age in our sam- 


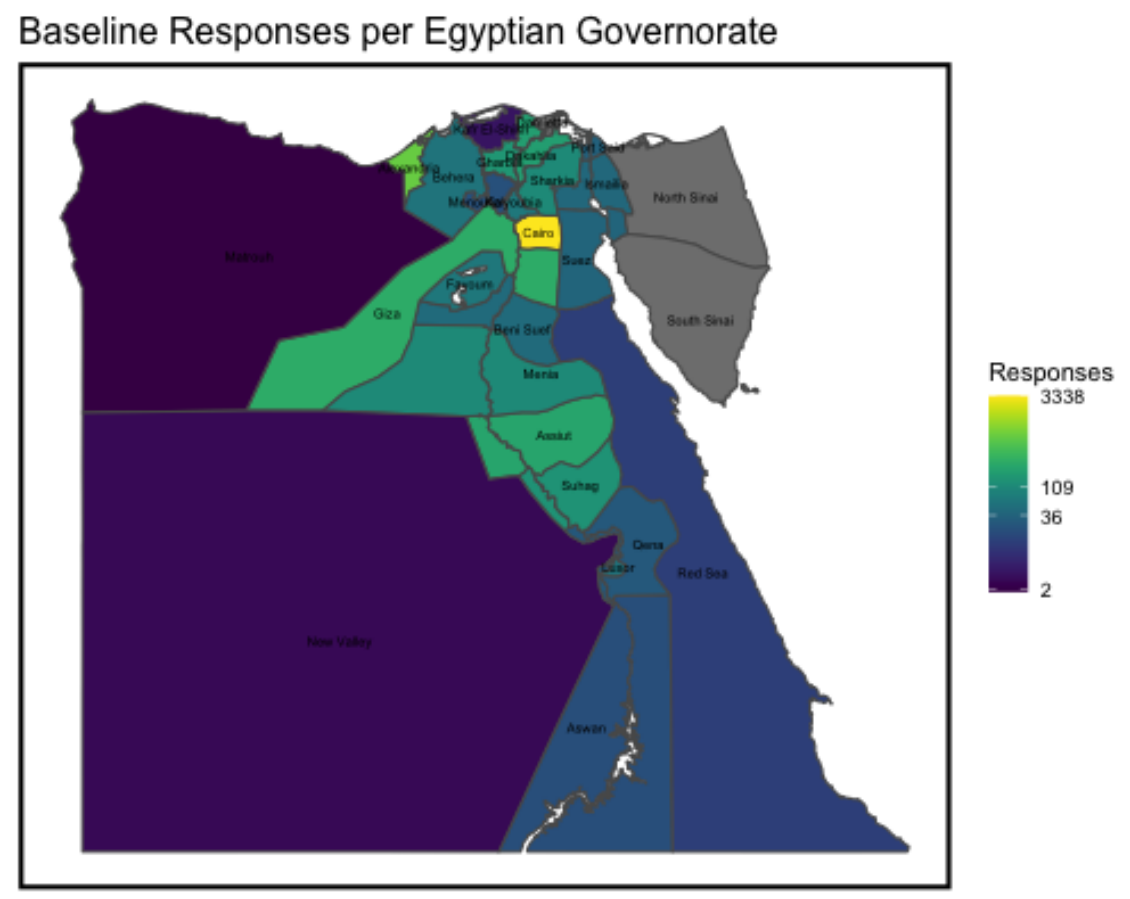

Figure 1: A map of baseline survey responses show that all but two governorates in Egypt are represented in our sample though more than half of the sample responded from Cairo.

ple was 30 , and $32 \%$ of our participants are single or engaged with the remaining married, divorced, or widowed.

We block randomized the dissemination of messages across the sample of WhatsApp and Facebook subscribers that responded to the baseline, as well as into reminders about the television show. In addition to a control, we had four treatment groups: those receiving the videos in WhatsApp Groups, individually via WhatsApp or individually via Facebook, as well as those receiving a reminder delivered via WhatsApp of a weekly television show. Because not all respondents provided Facebook information or sent us a Facebook message, we were able to match 993 who also provided Facebook information. We then block randomized in two batches: in groups of 10 for those with Facebook and WhatsApp accounts $(1 / 5$ - Control, 1/5 - WhatsApp Individual, 3/5 - Facebook Individual) and in groups of 50 for those without Facebook accounts but with WhatsApp accounts (1/5 - Control, 1/5 - TV Reminder, 1/5 WhatsApp Individual, 2/5 - WhatsApp Group). Table 1 describes this process.

Treatment Variants and Intervention Content: ECWR produced the weekly television program covering similar topics called Hekayat Nehad, or Nehad's Stories. The television shows aired on a popular satellite channel, Al Kahera Wa Al Nas, on Saturday evenings between 27 June, 2020 and September 5, 2020, for a total of 10 episodes. Respondents in the 

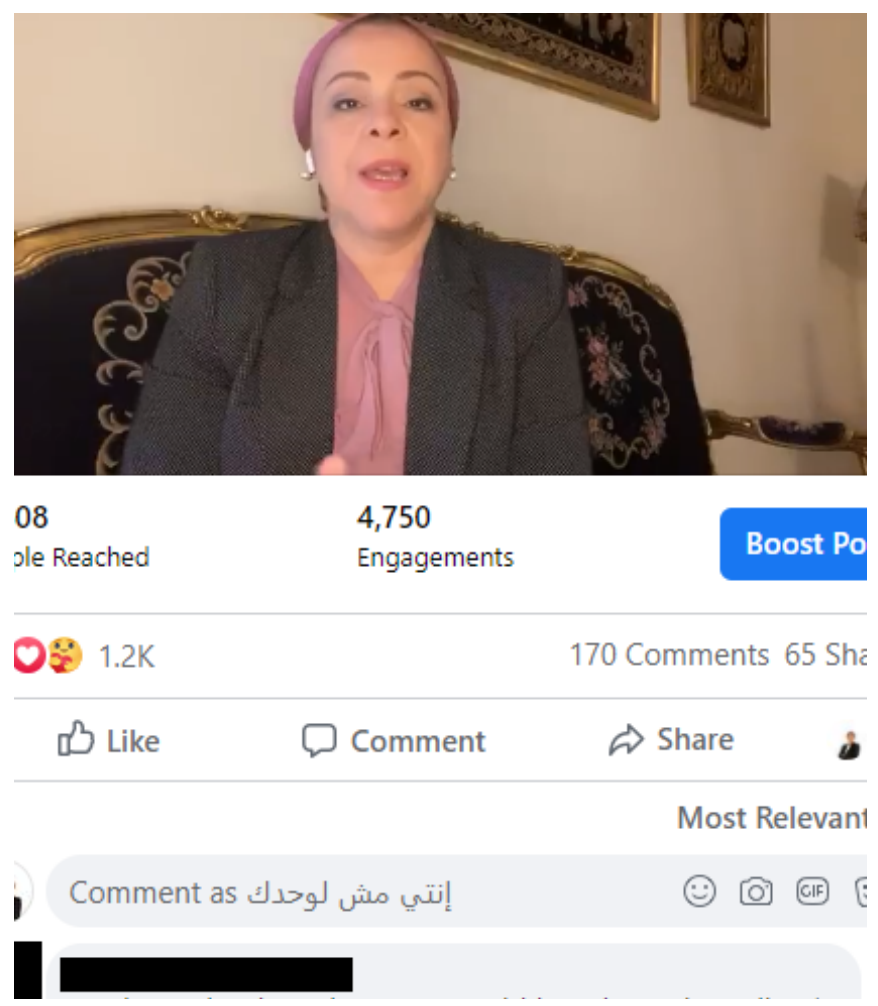

Figure 2: A welcome video posted on Facebook explaining the purpose of the study and inviting participation in the survey.

"Television Reminder" treatment received a WhatsApp message each Saturday informing them about the time and channel of the show for the final eight weeks of this period, from July 18, 2020 through September 5, 2020. These messages also pointed to the location of videos from previous episodes. ${ }^{34}$ The TV shows were around 25-30 minutes in length and covered a broad array of topics related to women's empowerment, sexual harassment, and violence against women in Egypt, as described in Table 35 in the Appendix. In the television show, Nehad Aboul Komsan sits in a television studio and speaks directly to the camera in a conversational tone.

Enrollees in the "Facebook," "WhatsApp Individual" or "WhatsApp Group" treatment received thirteen videos in the eight-week period between July 18, 2020 and September 5, 2020. Videos were sent at the same time as "Television Reminders" on Saturdays, or during the week on Tuesdays or Thursdays. The videos had a similar narrative style as the television show, with Aboul Komsann producing engaging, conversational content while speaking directly to the camera from a nicely-furnished home. Topics were selected to be in line with the content of the television show according to our partner's understanding of the needs of an Egyptian audience. The 5-9 minute videos often begin with the latest news or events in Egypt, before delving into substantive discussion of sensitive issues like divorce, female genital cutting (FGC), GBV in the workplace or in public, and IPV. Further details on the videos are in Table 34 in the Appendix. While the intervention began as centered

\footnotetext{
${ }^{34}$ Those assigned the television show reminders were initially distributed videos to previous shows.
} 


\begin{tabular}{|l|l|l|l|l|}
\hline Treatment & Assigned & $\begin{array}{l}\text { Blocking, Accts } \\
\text { w/FB }\end{array}$ & $\begin{array}{l}\text { Blocking, Accts } \\
\text { w/ WhatsApp }\end{array}$ & Treatment Description \\
\hline Control & 1160 & Blocks of 10,1/5 & Blocks of $50,1 / 5$ & No content \\
\hline Facebook & 586 & Blocks of 10,3/5 & NA & $\begin{array}{l}\text { Received links to website } \\
\text { with videos via Facebook, } \\
\text { and then WhatsApp }\end{array}$ \\
\hline $\begin{array}{l}\text { Remind } \\
\text { Show }\end{array}$ & 973 & NA & Blocks of $50,1 / 5$ & $\begin{array}{l}\text { Received TV show re- } \\
\text { minders via WhatsApp }\end{array}$ \\
\hline $\begin{array}{l}\text { WhatsApp } \\
\text { Group }\end{array}$ & 1946 & NA & Blocks of $50,2 / 5$ & $\begin{array}{l}\text { Received links to website } \\
\text { with videos in groups via } \\
\text { WhatsApp }\end{array}$ \\
\hline $\begin{array}{l}\text { WhatsApp } \\
\text { Ind }\end{array}$ & 1163 & Blocks of 10,1/5 & Blocks of $50,1 / 5$ & $\begin{array}{l}\text { Received links to website } \\
\text { with videos individually via } \\
\text { WhatsApp }\end{array}$ \\
\hline
\end{tabular}

Table 1: We block randomized assignment to treatment in two batches, according to whether accounts did and did not provide Facebook details through which to send content.

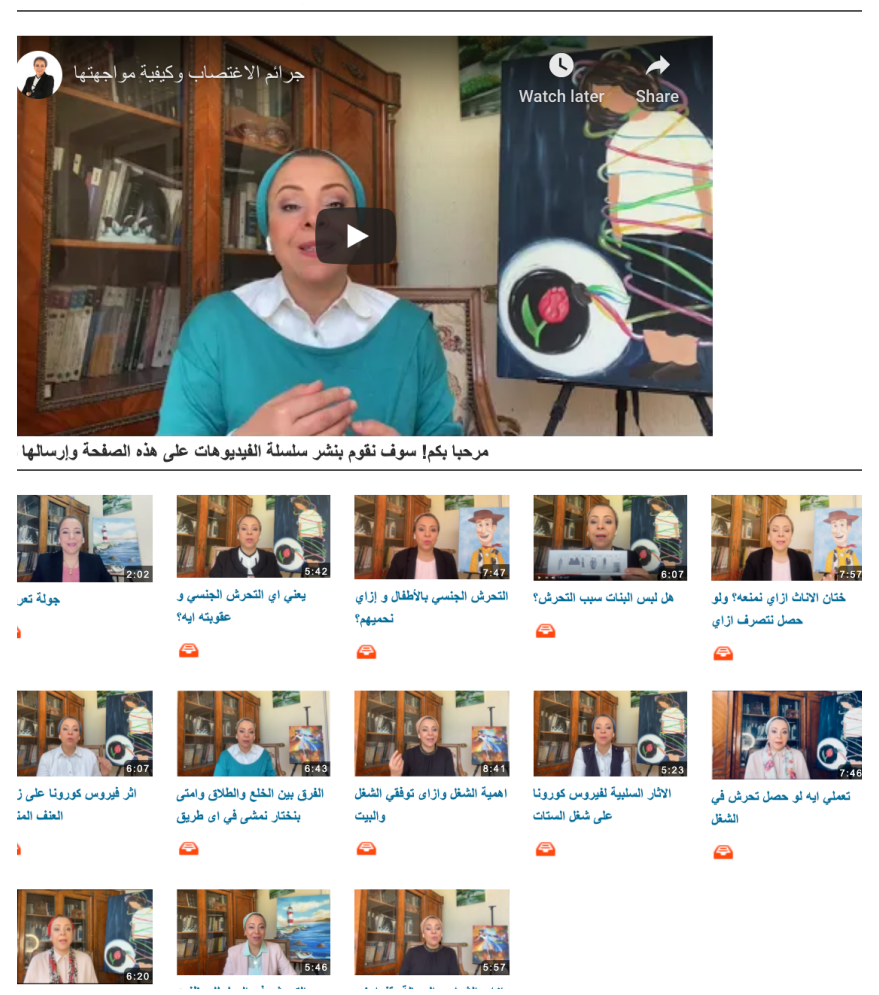

Figure 3: Users in the Facebook, WhatsApp Group, and WhatsApp Individual treatments received a link to a website, mshlwa7dek.org where all video messages were hosted.

around GBV and IPV, as with its TV show, ECWR elected to include content on topics such as FGC and workplace harassment in messaging in response to ongoing events in Egypt. 


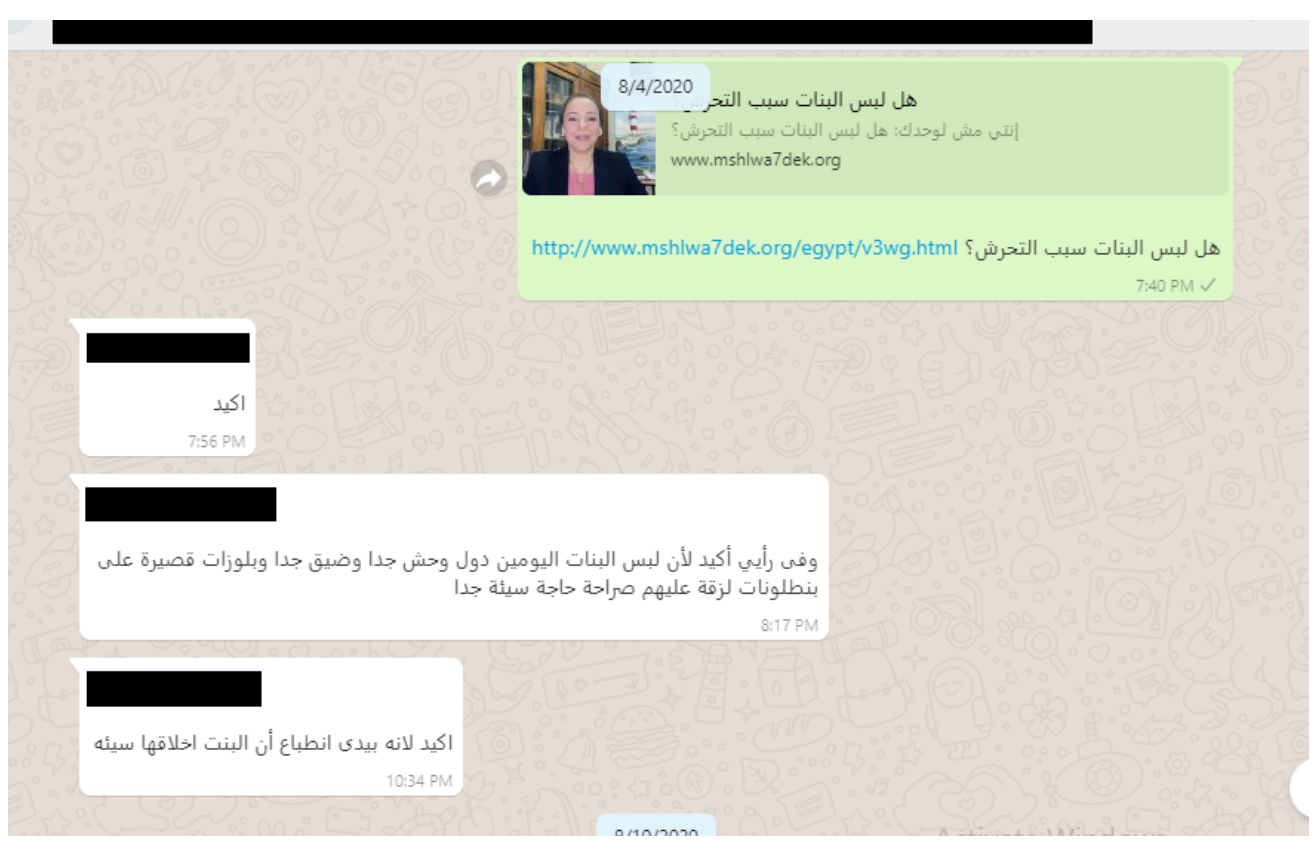

Figure 4: Delivery of a video titled "Is women's clothing the cause of harassment?" via WhatsApp.

The videos disseminated via WhatsApp and Facebook were uploaded via YouTube to a website, mshlwa7dek.org/egypt/. Figure 3 displays how this website appeared. Each link navigated to each individual video. Using a different, duplicated landing page for each treatment arm, we were able to measure aggregate visits per treatment. "TV Reminders" and "WhatsApp Individual" were sent using WhatsApp's Broadcast List functionality. Those in the "WhatsApp Group" treatment were assigned into groups ranging from 7 to 10 individuals, and video content was shared there. To understand if the videos generated conversation within groups, a group of researchers responsible for disseminating the messages manually coded aggregate discussion in the channels.

Figure 4, below, depicts how delivery via WhatsApp appeared on a phone to a single user. The video is titled "Is women's clothing the cause of harassment?", and members of the group respond, "Of course", "Clothes is definitely a reason. Especially nowadays, since women's clothes are very tight and inappropriate, it's just very bad." and, "And it causes harassment because it gives an impression the girl is ill-mannered." To other messages, users responded with words of encouragement of Nehad Aboul Komsan, with messages like, "Please talk about the causes of harassment, why it's increasing, and why women remain silent and fear speaking up, and why only women are blamed," or "The episodes are great. Keep going." Throughout the dissemination, however, we saw low levels of discussion on video content within groups.

We used Facebook's Custom Messages channel, which allows a Facebook Page to upload a list of information associated with a user and deliver a message directly to that user. According to Facebook's advertisement analytics, the rate of delivery was around $40 \%$. Because of a technical issue with accessing the main account, we transitioned to delivering 


\begin{tabular}{cccc}
\hline Assignment & Baseline & Endline & Response Rate \\
\hline Control & 1104 & 839 & 0.76 \\
Facebook & 565 & 418 & 0.74 \\
Remind_Show & 952 & 702 & 0.737 \\
WhatsApp_Group & 1879 & 1382 & 0.735 \\
WhatsApp_Ind & 1118 & 824 & 0.737 \\
\hline Total & 5618 & 4165 & 0.741 \\
\hline
\end{tabular}

Table 2: Response rates by assignment. This table displays response rates after removing those who responded twice to the endline survey.

messages through WhatsApp individually beginning with the 5th video, on August 11, 2020. As a result, users in this treatment received four videos over Facebook messenger, and 9 via WhatsApp, which is why our main first stage and reduced form specification will pool these two treatment arms. Figure 5 shows that visits to the video's landing pages increased following this shift to distribution via WhatsApp (52.5 landing page visits per video, compared with 38 on Facebook), which suggest that WhatsApp is a more effective platform for treatment delivery. In our primary analysis, we will pool individuals who received the messages via WhatsApp and Facebook individually.

The endline survey was disseminated via WhatsApp and SMS from September 10, 2020 through October 11, 2020. All individuals were sent messages via WhatsApp's Broadcast list functionality along with manual SMS for individuals who were no longer in our contact list. Researchers delivering the survey message used WhatsApp's delivery and read receipts functionality to determine whether these endline messages had been delivered, and sent SMSs to those who had not received the survey via WhatsApp. Of the 5,618 of respondents that completed the survey at baseline, 4,222 completed the endline survey, or 74.1\%. Table 2 shows that endline response rates were balanced across treatment conditions. Upon project completion, we disseminated all video content to those in the Control arm who had not received it over prior months.

\subsection{Measuring First Stage Delivery via Responses, Website Visits, and YouTube Analytics}

For all of these outcomes, important first stage measurement of treatment receipt will be whether an individual reports hearing about and receiving reminders on the television show Hekayat Nehad (E22, E23, E24, E25), ${ }^{35}$ or receiving videos via Facebook or WhatsApp (E35, E36). We also expect somewhat important first stage measurements to be reported watching of the television show and accurately describing its content (E21, E26, E27, E28), viewing and describing the content of WhatsApp videos (E37, E38, E39), and a range of questions about TV and social media consumption habits (E21, E33, E34). In addition, as in Table 3, we

\footnotetext{
${ }^{35}$ These variable names refer to question labels in the survey instrument in Appendix 8
} 


\section{Facebook Videos Landing Page Visits before and after Distribution Shift}

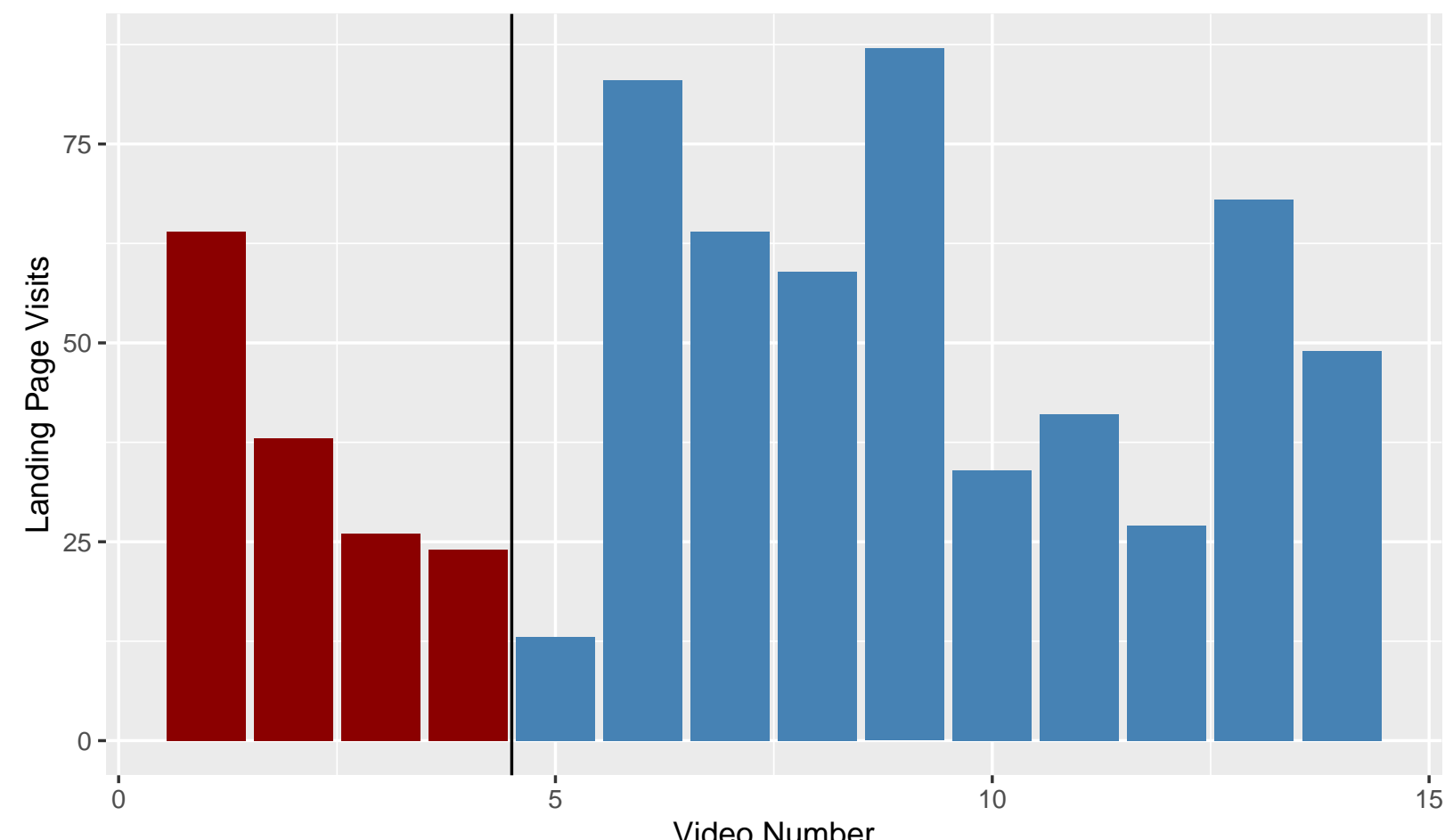

Video Number

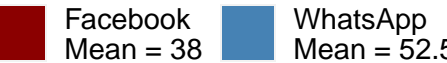

Figure 5: The figure shows differences in landing page visits (see more details on this below) in the "Facebook" treatment before and after the shift to distribution from Facebook Custom Messages to WhatsApp due to a technical issue with the main account.

will measure first stage treatment delivery via aggregate visits to different landing pages for individuals in the "WhatsApp Individual," "WhatsApp Group," and "Facebook" treatments. Beyond these self-reported measurements of treatment receipt, we use our YouTube channel to understand aggregate visits and views to the pages hosting the videos. ${ }^{36}$

On aggregate, Table 3, Figure 6 and Table 4 allow us to see that approximately half of the assigned users visited the site, and most users who visited the site accessed multiple pages and watched multiple videos. Over the course of the distribution and endline period (July 23 - October 10,2020), the website received 4,149 visits from Egypt (3,443 unique IP addresses, 1,558 Unique User Ids). The time spent on the site was roughly similar across treatment arms, at about 4 minutes, 1 second, but this hides substantial heterogeneity across users with some barely visiting the site and third quartile spending approximately 25 minutes. Similarly, YouTube records 3,270 views, with an average length of 3 minutes and

\footnotetext{
${ }^{36}$ This data has a few shortcomings: the website's tabulation of Unique User Ids assigns a cookie to each web browser, so that individuals accessing content across different devices are counted separately. Moreover, the mechanics of YouTube visit tabulation are opaque, and YouTube likely only counts views above a certain threshold.
} 

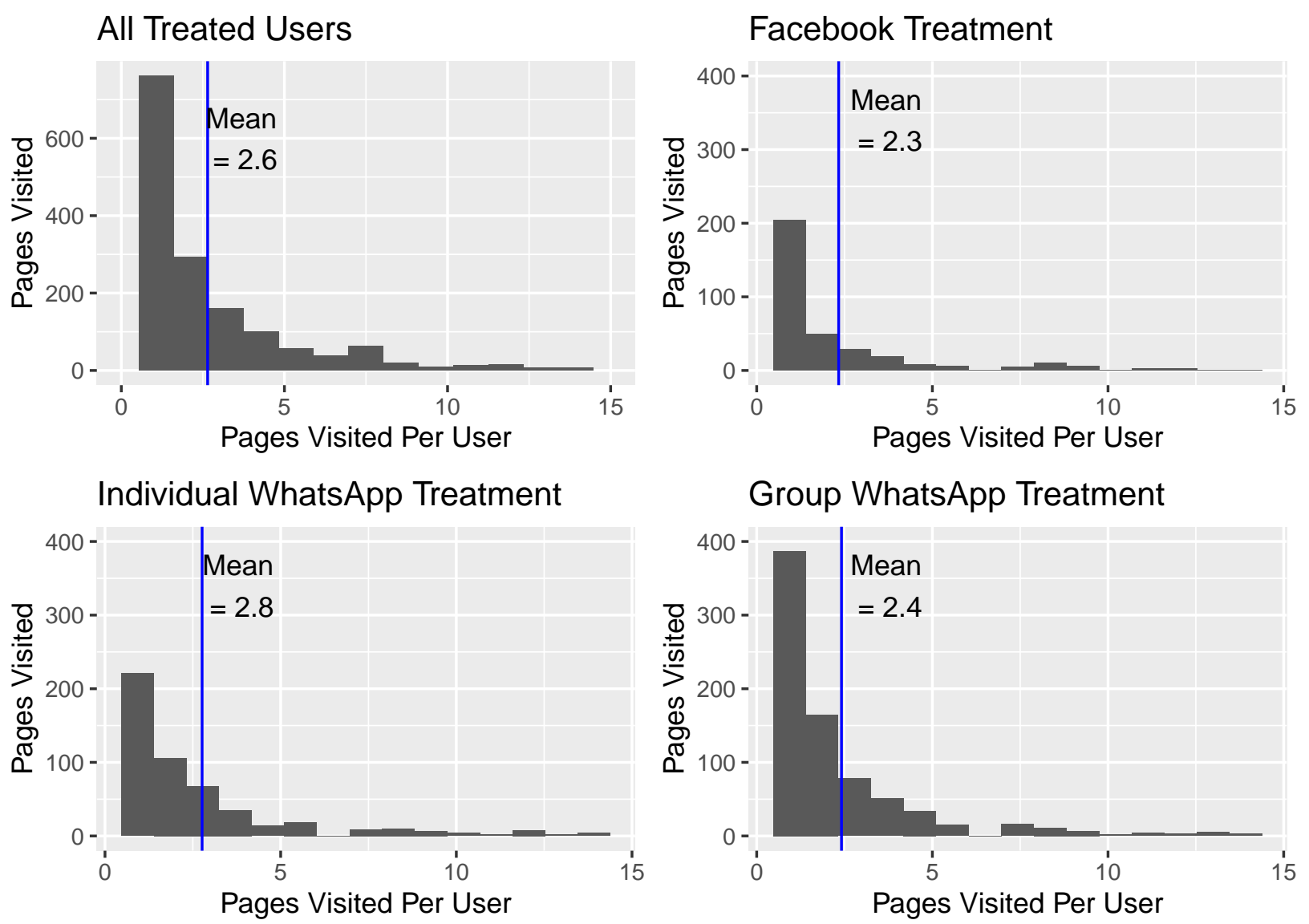

Figure 6: Across treatment arms, the mean user visited approximately 2.6 pages on the site. The median user visited two or three pages..

9 seconds. As clear from Table 4, the lower incidence of viewership in YouTube is partially due to its stricter definition of viewership. There is no analogous way to measure viewing of the television show, for those who received a reminder to view the program.

The data in Table 3 suggest that, compared with individuals in the Whats App Group treatment, those in the Facebook and Whats App Individual treatment arms, on average, engaged $25 \%$ more with the treatment content, as measured by the percentage of those visiting the website and viewing its content relative those assigned to treatment. Figure 6 shows that the mean unique user visited two to three video sites of the thirteen videos distributed, and the distinction between treatment arms is less clear.

\section{Variation and Correlates at Baseline}

We present the correlates and variation of some of our baseline outcomes, which informed our heterogeneous effect analysis. Figures 7 and 8 show the baseline level of variation in 


\begin{tabular}{ccccccc}
\hline Assignment & Assigned & Unique Users & Unique IPs & Total Actions & IP/Tot. & Med. Time \\
\hline FB & 586 & 345 & 597 & 1347 & 1.02 & $4: 02$ \\
WA Ind. & 1163 & 509 & 1178 & 2463 & 1.01 & $4: 01$ \\
WA Group & 1946 & 781 & 1671 & 3280 & 0.86 & $3: 57$ \\
\hline Total & 3695 & 1635 & 3446 & 7090 & 0.93 & $4: 01$ \\
\hline
\end{tabular}

Table 3: Our website's reported number of unique users, unique IPs, and total actions according to treatment arm. A Unique User is determined via cookies and thus corresponds to a specific individual in a particular device. Note that this table reports different treatment assignment numbers than Table 1 as it includes assignments who may have responded twice to the endline survey.
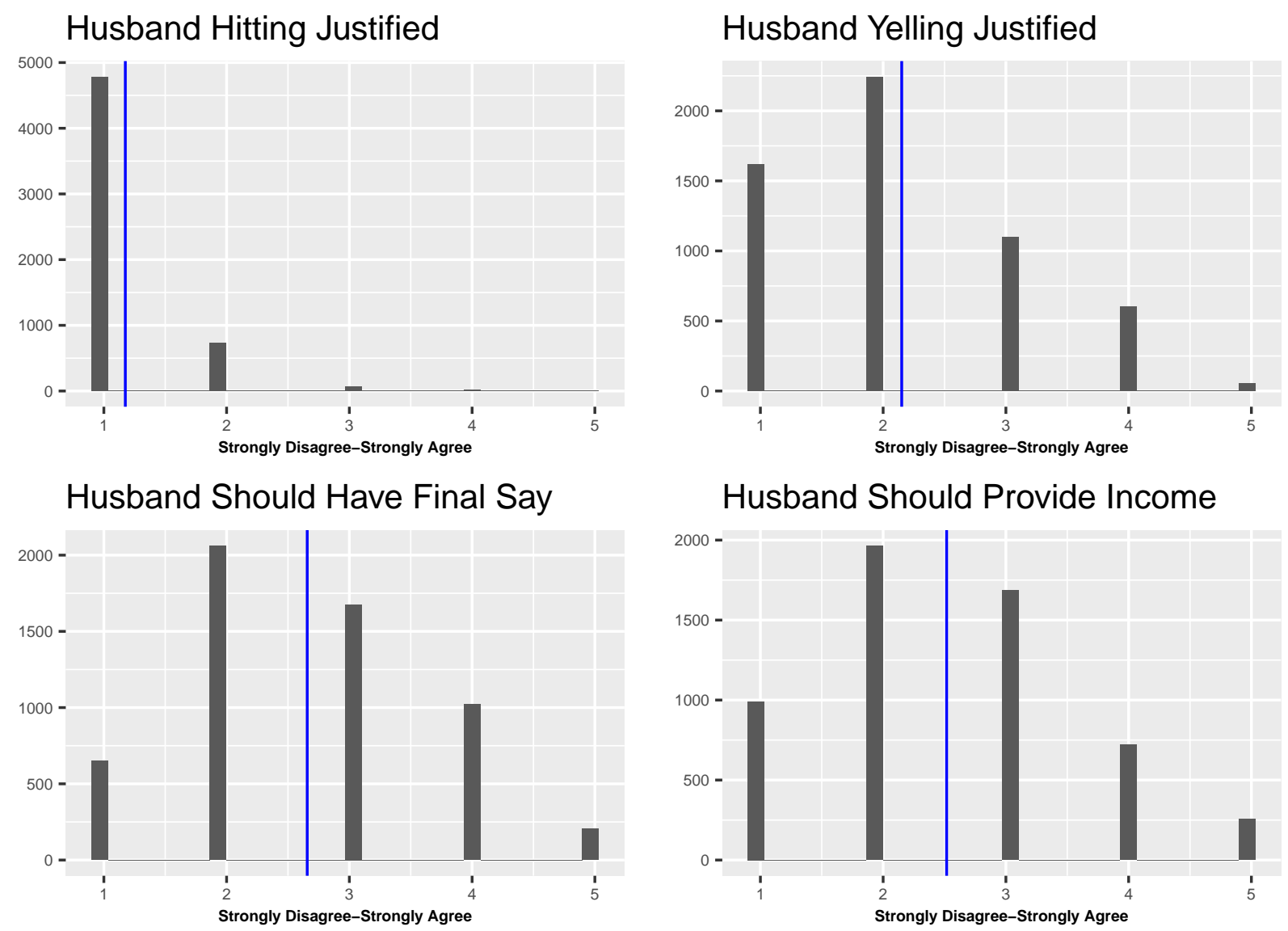

Figure 7: The above plot shows variation in responses to key attitudinal questions at baseline. The plot shows that there is little variation in attitudes toward the justifiability of husbands sometimes hitting or beating their wives. There is more variation in attitudes of whether a husband is sometimes justified in yelling at their wives, as well as in whether husbands should have final say in all decisions regarding the family and whether husbands should provide the income.

our principal attitudes questions at baseline, centered on justification of violence and gender roles within the family. The figure shows that while there is broad rejection of whether 


\begin{tabular}{|c|c|c|c|c|c|c|c|}
\hline Title & Date & YT Views & $\begin{array}{l}\text { Web } \\
\text { Visits }\end{array}$ & $\begin{array}{l}\text { YT } \\
\text { Total } \\
\text { (Hours) }\end{array}$ & $\begin{array}{l}\text { Web } \\
\text { Total } \\
\text { (Hours) }\end{array}$ & $\begin{array}{l}\text { YT } \\
\text { Avg. } \\
\text { View }\end{array}$ & $\begin{array}{l}\text { Web } \\
\text { Avg. } \\
\text { Visit }\end{array}$ \\
\hline $\begin{array}{l}\text { What is sexual harassment and } \\
\text { what is its penalty? }\end{array}$ & Jul 24 & 535 & 682 & 22.80 & 40.26 & $0: 02: 33$ & 0:03:33 \\
\hline $\begin{array}{l}\text { Sexual harassment of children } \\
\text { and how to protect them? }\end{array}$ & Jul 31 & 391 & 493 & 24.42 & 40.66 & $0: 03: 44$ & $0: 04: 57$ \\
\hline $\begin{array}{l}\text { Are womens clothes the cause of } \\
\text { sexual harassment? }\end{array}$ & Aug 3 & 324 & 372 & 15.26 & 21.59 & $0: 02: 49$ & 0:03:29 \\
\hline FGC and how to stop it? & Aug 7 & 268 & 286 & 18.19 & 22.16 & 0:04:04 & 0:04:39 \\
\hline $\begin{array}{l}\text { Impact of COVID-19 on increas- } \\
\text { ing domestic violence }\end{array}$ & Aug 11 & 212 & 235 & 9.84 & 17.85 & $0: 02: 47$ & $0: 04: 33$ \\
\hline $\begin{array}{l}\text { Rape crimes and how to fight } \\
\text { them and COVID-19 }\end{array}$ & Aug 14 & 207 & 226 & 9.97 & 12.02 & $0: 02: 53$ & 0:03:11 \\
\hline $\begin{array}{l}\text { The difference between divorce } \\
\text { and Khul and when to choose ei- } \\
\text { ther? }\end{array}$ & Aug 17 & 268 & 230 & 15.09 & 18.55 & $0: 03: 22$ & 0:04:50 \\
\hline $\begin{array}{l}\text { The importance of work and how } \\
\text { to balance between work and } \\
\text { home? }\end{array}$ & Aug 21 & 281 & 268 & 18.03 & 21.35 & $0: 03: 51$ & 0:04:47 \\
\hline $\begin{array}{l}\text { The negative effects of Covid-19 } \\
\text { on women's work }\end{array}$ & Aug 25 & 107 & 96 & 5.22 & 4.60 & $0: 02: 55$ & $0: 02: 52$ \\
\hline $\begin{array}{l}\text { How to deal with workplace ha- } \\
\text { rassment? }\end{array}$ & Aug 26 & 175 & 143 & 9.83 & 10.84 & $0: 03: 22$ & 0:04:33 \\
\hline $\begin{array}{l}\text { How to act if you saw someone } \\
\text { harassing a colleague at work? }\end{array}$ & Aug 28 & 146 & 110 & 7.10 & 7.86 & $0: 02: 55$ & $0: 04: 17$ \\
\hline $\begin{array}{l}\text { Dealing with workplace harass- } \\
\text { ment for new employees }\end{array}$ & Sep 7 & 172 & 146 & 7.84 & 10.55 & $0: 02: 44$ & $0: 04: 20$ \\
\hline $\begin{array}{l}\text { How can men stand against vio- } \\
\text { lence against women? }\end{array}$ & Sep 9 & 184 & 184 & 7.84 & 21.02 & $0: 02: 33$ & $0: 06: 51$ \\
\hline Totals & & 3270 & 3471 & 13.19 & 19.18 & $0: 02: 59$ & $0: 04: 22$ \\
\hline
\end{tabular}

Table 4: Website and YouTube analytics show that earlier videos received higher numbers of visitors and views. The website analytics report higher numbers because they measure individual visits and total duration on the site, whereas YouTube measures time spent viewing the content.

husbands hitting their wives can be justified, there is more variation in views toward the justifiability of yelling. Toward family roles, there is broad variation in whether husbands should have the final say in all matters concerning the family and whether a husband should always provide the household income, but broad rejection of prioritizing education based upon gender. There is some variation in whether respondents believe women will have equal say and equal rights in the future, with most respondents holding a positive outlook.

Appendix Tables 5, 6, 7, 8, 13 and 14 examine the relationships between age, education, income and marital status on attitudes and outlooks. They show that older women are more likely to agree that husbands should provide income and should have the final say in household decisions, but more likely to reject violence and equally likely to prioritize education for men or say hitting is justified. Older women are slightly more likely to believe women will achieve greater gender equality in the future, in terms of more equal legal rights, access to education, economic opportunities, and say in their families. Women with a BA degree are more likely to reject violence, equally likely to agree with the other attitudinal 

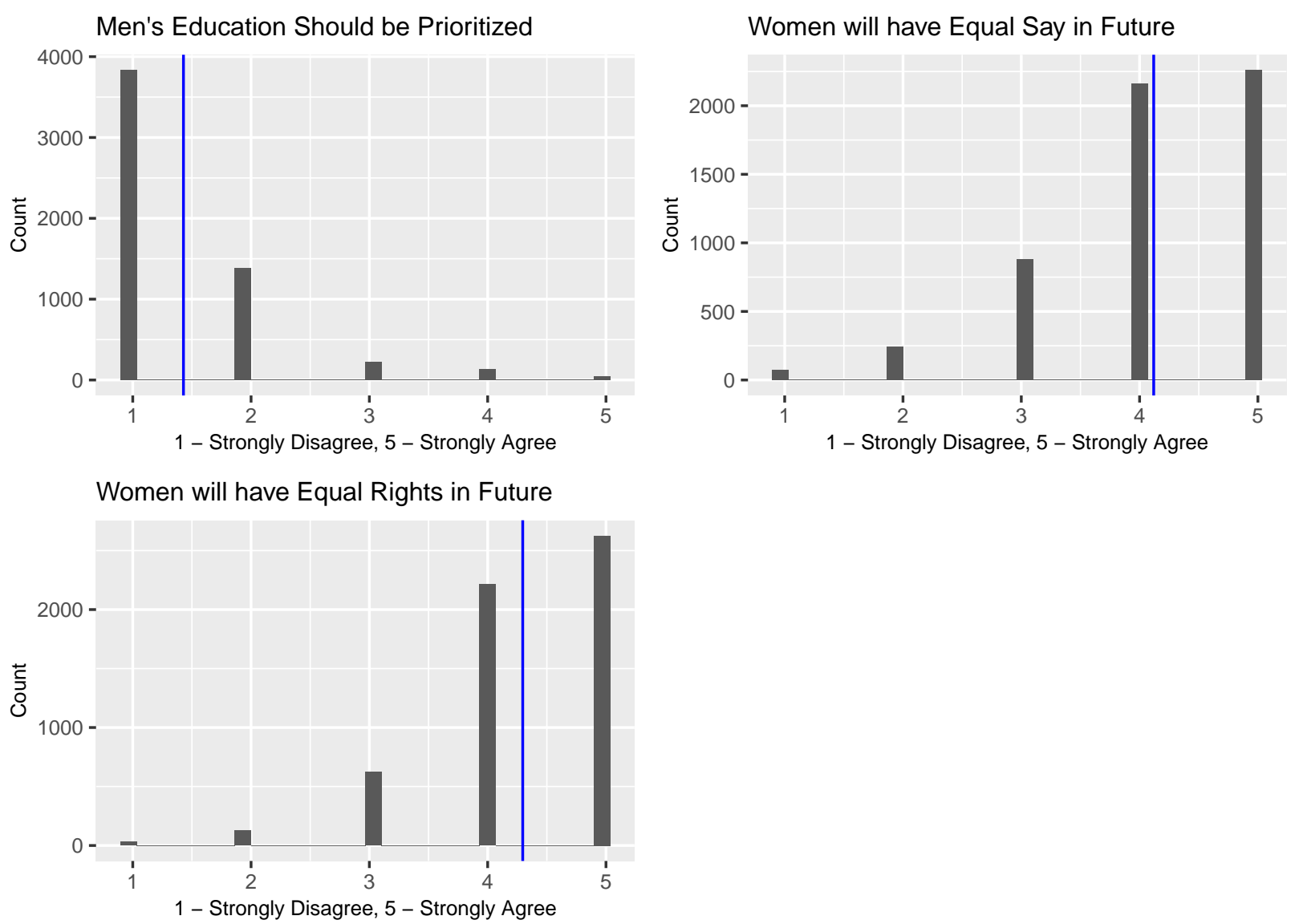

Figure 8: The above plot shows variation in responses to key attitudinal questions at baseline. The plot shows that most respondents at baseline rejected the notion that male education should be prioritized. There is more variation in questions on future outlook, but most believe women will have equal say and equal rights in the future.

measures, and hold more negative outlooks toward women's equality in the future. Women facing fewer financial struggles before COVID-19 are less likely to say that a husband should provide the income when necessary, and also more likely to reject violence. Similar to women with a BA, they hold more negative outlooks toward equality in the future. Married women (with unmarried women defined as single, engaged, divorced, separated, and widowed; 3,042 in sample are married) are more likely to say that husbands should ideally provide income and should have final say in family affairs, but equally likely to report prioritizing men's education or to reject violence. Married women are less likely to say that in the future women will have an equal say in decisions regarding the future. Appendix Tables 16 and 17, meanwhile, show an intuitive correlation that women who hold attitudes less in favor of gender equality and more accepting of violence are less likely to say that women will have equal say and rights in the future.

Tables 18, 19, 20, 21 and 22 show the relationships between income, education, age, marital status, total in the household, COVID-19 income decline and attitudes and knowledge of online resources or organizations advising women affected by domestic violence. More 
educated, more affluent and older women are more likely to be familiar with an organization or an online resource. ${ }^{37}$ Married and unmarried women are equally likely to know of an online organization or resource. Individuals holding views that are more accepting of violence and less favorable toward gender equality are less likely to know online resources or organizations. Total individuals in the household and reported decline in income during the COVID-19 pandemic showed little relationship to knowledge.

\subsection{Hypothetical Behavior at Baseline}

Tables 23, 24 and 25 show that more educated women are more likely and older women less likely to report to authorities, and both are equally likely to look for resources or contact an online organization in a scenario where a friend has been affected by domestic violence. Married women are less likely to report to authorities, look for online resources, or contact in organization in the same scenario. Income has no significant impact on these hypothetical behaviors. Tables 26, 27 and 28 show negative relationships between attitudes more accepting of violence and gender inequality and willingness to contact authorities, look for online resources, or contact an organization in a scenario where a friend has been affected by domestic violence.

\subsection{Reported Experience of Violence at Baseline}

Tables 29 and 30 show that while there is no relationship between education (attaining a BA) and experiencing yelling or hitting in the months before the COVID-19 pandemic, women in more comfortable financial situations, married women, surprisingly, and younger women were less likely to witness or experience violence. Tables 32 and 33, meanwhile, show that individuals who hold attitudes less in favor of gender equality and more accepting of violence were less likely to report experiencing violence via yelling or hitting in the months prior to COVID-19.

\section{Empirical Framework}

Throughout most of our analysis, we will estimate balance and treatment effects respectively for baseline covariates and endline outcomes by regressing them against disaggregated (i.e., all four possible combinations) treatment and pooled (i.e., any treatment, or social media and TV) indicators.

Consider individual i in randomization block b. Our most general baseline equation

\footnotetext{
${ }^{37}$ Note the knowledge questions are measured crudely in terms of providing any text based answer of knowing an organization, as opposed to a necessarily correct one.
} 
will be the following intent-to-treat (ITT) specification:

$$
\begin{gathered}
Y_{i}=\alpha_{0}+\alpha_{1} \text { WhatsAppIndividual }+\alpha_{2} \text { WhatsAppGroup }+\alpha_{3} \text { FacebookIndividual }+ \\
\alpha_{4} \text { TVReminder }+\Omega X_{i}+\gamma_{b}+\varepsilon_{i}
\end{gathered}
$$

Where the variables are defined as follows:

- $\alpha_{1}$ is a dummy equal to 1 if individual $\mathrm{i}$ is treated with WhatsApp Individual;

- $\alpha_{2}$ is a dummy equal to 1 if individual i is treated with WhatsApp Group

- $\alpha_{3}$ is a dummy equal to 1 if individual $\mathrm{i}$ is treated with Facebook Individual

- $\alpha_{4}$ is a dummy equal to 1 if individual $\mathrm{i}$ is treated with TV Reminder.

- $\gamma_{b}$ is a randomization block fixed effect;

- $X_{i}$ are individual baseline controls from the corresponding family of outcomes. This will be a vector of demographic covariates and baseline outcomes. We will show estimates for a version of the ITT equation, without $X_{i}$, with $X_{i}$ and with $X_{i}$ chosen through machine learning considering baseline outcomes beyond the lagged dependent variable (Athey and Imbens (2019); Bloniarz et al. (2016)).

Since, as explained above, the delivery of messages through Facebook had to be replaced with WhatsApp Individual delivery, while we will run balance tables for separate indicators, to maximize power, we will pool Facebook and WhatsApp Individual delivery.

For our main estimates, we will also considering pooling Facebook, WhatsApp Individual and WhatsApp Group delivery as a measure of the overall impact of the video delivered via social media compared with the traditional media TV reminders, and in recognition that there was relatively little interaction in the WhatsApp Groups.

Standard errors will not be clustered since the unit of randomization was the individual. We will measure our outcomes using standardized z-score (Kling et al. (2007)), and as robustness, inverse covariance weighted (ICW) indexes. We will weigh the elements of the indexes equally. The coefficients used to test our primary hypotheses will be $\alpha_{j}$ for $\mathrm{j}=1$ to 4 . We will use one-sided hypothesis tests when we have hypothesized a direction and two-sided hypothesis tests where we have not. For each hypothesis we will test our hypothe-

ses individually unless otherwise noted. When testing hypotheses jointly, we will make the necessary adjustments for multiple hypotheses testing.

\subsection{First Stage Regressions}

We will start by analyzing the relative effectiveness of the treatment arms (some pooled, as explained above) at getting participants to consume the treatment information (see outcomes 
below). While most of our analysis will focus on ITT estimates, we might also consider instrumental-variable estimates. If so, in the case that the pooled treatment assignments do not provide a sufficiently strong instrument, we will use machine learning to select the optimal combination of treatment indicators and baseline covariates as instruments (Belloni et al. (2012); Chernozhukov et al. (2015)).

\subsubsection{Primary First Stage Hypotheses and Measurement of Key Variables}

Hypotheses 1 and 2 state that treated individuals are more likely to report receiving and consuming the content delivered via WhatsApp, Facebook, and Television. We will measure this via reported receipt, reported viewing, and accurate recollection of content (Variables E20 through E28, E33 through E40). Hypothesis 3 predicts individuals who receive the content via WhatsApp Group will report higher levels of reported receipt, viewing, and accurate recollection of content, especially if groups engaged in discussions around the content delivered.

\subsection{Reduced Form Regressions}

Our primary focus is on attitudinal effects, future outlook, knowledge, and hypothetical behavior.

\subsubsection{Primary Reduced Form Hypotheses and Measurement of Key Variables}

As explained in the literature and theory of change, our study focuses on whether information disseminated by a high-status figure to a large number of individuals can shift attitudes about gender equality and the justifiability of domestic and gender based violence, as well as knowledge about resources, hypothetical behavior, and revealed preferences. We now articulate how the hypotheses from the theory of change translate into predictions regarding intent-to-treat (ITT) treatment effects. Measurement of the relevant variables in these hypotheses is discussed in the following section.

1. Attitudes: Hypothesis 4: Any treatment assignment positively shifts individuals' attitudes in favor of more equal gender roles within the family, reduces their acceptance of the justifiability of GBV and IPV, and shifts their perception of violence against women as a problem.

2. Future Outlook: Hypothesis 6 Individuals who are targeted information messages or TV reminders will be more likely to express optimism about women's equality and empowerment in the future, relative to those on the control group. 
3. Knowledge: Hypothesis 7: Treated individuals will be more likely to exhibit greater knowledge, particularly about resources.

4. Hypothetical and Observed Behaviors: Hypothesis 8: Treated individuals will be more likely to recommend to seek online resources or contact a local organization in a hypothetical scenario where a friend or family member faces violence. Similarly, treated individuals should be more likely to report having themselves accessed online resources and contacted an organization that supports and advises women.

5. Revealed Preferences: Hypothesis 9: Any treatment assignment increases the likelihood that an individual donated to an NGO supporting women's empowerment in Egypt.

The above outcomes are measured as follows:

1. Attitudes: A range of questions asked about attitudes toward female empowerment, including the husbands role in the family, and the role of women in the workplace (B41-E41, B42, B43-E43, B44-E44, B45, E48). We also included attitude outcomes as they related to the justifiability of domestic violence and street harassment, definitions of and norms around interfering in sexual harassment, and female genital cutting (E49 to E56), and true/false questions to measure perceptions based attitudes related to the consequences of sexual harassment, FGC, and female empowerment (E57 to E60). Lastly, we measure in-survey reporting around sexual violence, domestic violence, and sexual assault with questions about hearing of or experiencing yelling, violence, or sexual assault before COVID-19 both at baseline and endline (B61-E61, B63-E63, E65), which allows measuring the perceived stigma of reporting of violence.

2. Future Outlook: B45-E45, B46-E46 ask about beliefs in women's roles in the future, measuring sense of efficacy as it relates to female empowerment.

3. Knowledge about Resources: We measure knowledge of resources through questions pertain specifically to knowledge of organizations and online resources in Egypt (E76, E77, B78-E78, B81-E81).

4. Hypothetical Behavior: We measure whether a respondent recommends to look for online resources and contact organizations to a friend has been exposed to domestic violence (B70-E70 and B71-E71), or exposed to sexual assault or sexual harassment (E74 and E75). ${ }^{38}$

5. Observed Behavior: We measure whether respondents have looked for or accessed online resources and contacted local organizations (B80-E80 and B83-E83).

6. Revealed Preference: We measure revealed preference through a willingness to make a donation to an organization supporting women's empowerment (E84).

\footnotetext{
${ }^{38}$ We also measure views about speaking with a husband or immediate family and contacting authorities in these hypothetical cases (B67-E67 to B69-E69 and E72 to E73), but as discussed above, we believe that our intervention unlikely to shift those views.
} 


\subsection{Secondary Hypotheses and Heterogeneous Effects}

Our study also seeks to highlight the mechanisms underlying any effects we find, as described in the Literature Review and Theory of Change sections.

Attitudes and Communal Distribution: Hypothesis 5: Individuals who are targeted treatment information via collective channels such as WhatsApp group or TV will exhibit stronger attitudinal changes.

Ceiling Effects: Treated individuals who exhibit high levels of knowledge at baseline will exhibit smaller treatment effects in knowledge.

Heterogeneous Effects on Behaviors: Treated individuals with lower baseline knowledge will be more likely to exhibit positive treatment effects on recommending to seek online resources or contacting an organization and themselves doing so. If there are limited treatment effects on attitudes, there should also be greater treatment effects on those outcomes among those with higher baseline attitudes in favor of gender equality and rejecting of violence.

All the variables related to these hypotheses were already introduced in the previous section. We will also look at heterogeneous effects on variables that predict baseline attitudes and knowledge about resources. These predictive variables will include:

- Age (B2-E2) and, if married, age differential with husband (B4-E4); ${ }^{39}$

- Whether a husband lives in the household (B3 and B6), ${ }^{40}$

- Level of education and, if married, husband's education (B10, B11)

- Number of children and individuals in the household (B7, B8, B9)

- Shifts of an individual or spouse to spending more time in the house due to COVID-19 (B12, B13, B14, B15) and COVID-19 induced financial stress (B16).

Due to the large number of predictors, in addition to the baseline outcomes on attitudes and willingness to seek external resources, we will use machine learning to analyze which the best predictors.

\footnotetext{
${ }^{39}$ Table 11 shows that a larger age gap between husband and wife translates into women being more likely to say husband should earn income, and justify yelling.

${ }^{40}$ Of 3,042 married women, 582 husbands lived away some or all of the time, Table 12 shows that those who have a husband living at home hold views far more likely to reject violence, far more likely to hold views favoring gender equality. This may just be a function of income, with poorer women married to those who work as migrant laborers abroad. Women with husbands living outside the home were far more likely before COVID to say that their income does not meet their expenses.
} 


\subsection{Topic Level Outcomes}

In principle, it is possible that individuals are more receptive or face lower barriers to attitudinal and behavioral change on some components of gender equality or some forms of harassment and violence. At the topic level, we will separately analyze our outcomes as follows:

Female Empowerment: We study attitudes toward female empowerment with questions about family roles and the role of women in the workplace (B41-E41, B42, B43E43, E48), as well as questions related to efficacy and the perceived status of women in the future (B46-E46, B47-E47). We asked factual questions to measure knowledge of the legal system in Egypt and medical knowledge, with questions about difference between divorce and $K_{h u l}{ }^{41}$, the legal age of marriage, and female genital cutting (E58, E59, E60).

Domestic Violence: We study attitudes toward domestic violence (B44-E44, B45), reported experience of domestic violence (B61-E61, B62-E62, B63-E63, B64-E64, B79E79, B82-E82), and hypothetical behavior in a scenario where a friend is exposed to domestic violence (B67-E67, B68-E68, B69-E69, B70-E70, B71-E71).

Sexual Harassment and assault: We add a range of questions on attitudes toward sexual harassment (E49, E50, E51, E53, E55), centered on its justifiability, sexual harassment in the workplace, and norms around interference. We also measure knowledge of sexual harassment in Egypt's legal system (E57), and hypothetical behavior in a scenario where a friend has been exposed to sexual harassment or assault (E72, E73, E74, E75). We asked one attitudinal question about sexual assault (E54), as well as questions about reported experience before or during COVID-19 (E65, E66).

For domestic violence, sexual harassment, and sexual assault, we also measure knowledge about resources (B78-E78, B81-E81), accessing resources (B79-E79, B82-E82), and contacting organizations (B80-E80, B83-E83) through a series of questions about knowledge of and accessing online resources or a supportive organization during the COVID-19 pandemic.

\subsection{Measurement issues}

Social Desirability Bias: We also measure whether individuals report contacting organizations or seeking online resources for women facing domestic violence, sexual harassment or sexual assault before COVID-19 both at baseline and endline (B79-E79, B82-E82). Treatment effects on changes between baseline and endline outcomes would reflect treatment effects on social desirability bias.

\footnotetext{
${ }^{41} \mathrm{~A}$ procedure rooted in Islamic law which allows a woman to initiate a separation or divorce from her husband but may require return of a dowry and may not provide access to the same legal rights, like alimony.
} 


\subsection{Data Cleaning}

We will follow a basic procedure for cleaning our variables.

1. We will code "don't know" and "refuse" answers as zero and include controls for such missingness, which will also be interacted with other regressors whenever appropriate.

2. We will check for balance on missing values (after re-coding "don't know" and "don't want to say" as missing) on our outcome variables, and test the sensitivity of our results to different assumptions on the missing data. In particular, if missignness of the outcome variables is correlated with treatment assignment, we will implement Manski-Horowitz bounds (i.e., coding all missing values as either zero or one). 


\section{References}

Abramsky, T., K. Devries, L. Kiss, J. Nakuti, N. Kyegombe, E. Starmann, B. Cundill, L. Francisco, D. Kaye, T. Musuya, et al. (2014). Findings from the sasa! study: a cluster randomized controlled trial to assess the impact of a community mobilization intervention to prevent violence against women and reduce hiv risk in kampala, uganda. $B M C$ medicine 12(1), 122.

Abramsky, T., K. M. Devries, L. Michau, J. Nakuti, T. Musuya, L. Kiss, N. Kyegombe, and C. Watts (2016). Ecological pathways to prevention: How does the sasa! community mobilisation model work to prevent physical intimate partner violence against women? BMC public health 16(1), 339.

Adida, C., J. Gottlieb, E. Kramon, and G. McClendon (2020). When does information influence voters? the joint importance of salience and coordination. Comparative Political Studies 53(6), 851-891.

Agüero, J. M. (2020). Covid-19 and the rise of intimate partner violence. World development, 105217.

Alatas, V., A. Banerjee, A. G. Chandrasekhar, R. Hanna, and B. A. Olken (2016). Network structure and the aggregation of information: Theory and evidence from indonesia. American Economic Review 106 (7), 1663-1704.

Alebel, A., G. D. Kibret, F. Wagnew, C. Tesema, A. Ferede, P. Petrucka, F. T. Bobo, M. Y. Birhanu, A. A. Tadesse, and S. Eshetie (2018). Intimate partner violence and associated factors among pregnant women in ethiopia: a systematic review and metaanalysis. Reproductive health 15(1), 1-12.

Arias, E. (2019). How does media influence social norms? experimental evidence on the role of common knowledge. Political Science Research and Methods 7(3), 561-578.

Athey, S. and G. Imbens (2019). Machine learning methods economists should know about, arxiv.

Badrinathan, S. (2020). Educative interventions to combat misinformation: Evidence from a field experiment in india.

Bandura, A. (2002). Social cognitive theory in cultural context. Applied psychology 51(2), 269-290.

Bandura, A. (2003). Social cognitive theory for personal and social change by enabling media. In Entertainment-education and social change, pp. 97-118. Routledge.

Banerjee, A., E. L. Ferrara, and V. Orozco (2019). Entertainment, education, and attitudes toward domestic violence. In AEA Papers and Proceedings, Volume 109, pp. 133-37.

Banerjee, A., S. Kumar, R. Pande, and F. Su (2011). Do informed voters make better choices? experimental evidence from urban india. 
Belloni, A., D. Chen, V. Chernozhukov, and C. Hansen (2012). Sparse models and methods for optimal instruments with an application to eminent domain. Econometrica 80(6), 2369-2429.

Blair, G., R. Littman, and E. L. Paluck (2019). Motivating the adoption of new communityminded behaviors: An empirical test in nigeria. Science advances 5(3), eaau5175.

Bloniarz, A., H. Liu, C.-H. Zhang, J. S. Sekhon, and B. Yu (2016). Lasso adjustments of treatment effect estimates in randomized experiments. Proceedings of the National Academy of Sciences 113(27), 7383-7390.

Boas, T. C., F. D. Hidalgo, and M. A. Melo (2019). Norms versus action: Why voters fail to sanction malfeasance in brazil. American Journal of Political Science 63(2), 385-400.

Boserup, B., M. McKenney, and A. Elkbuli (2020). Alarming trends in us domestic violence during the covid-19 pandemic. The American Journal of Emergency Medicine.

Bourey, C., W. Williams, E. E. Bernstein, and R. Stephenson (2015). Systematic review of structural interventions for intimate partner violence in low-and middle-income countries: organizing evidence for prevention. BMC public health 15(1), 1165.

Bowles, J., H. Larreguy, and S. Liu (2020). Countering misinformation via whatsapp: Preliminary evidence from the covid-19 pandemic in zimbabwe. PloS one 15(10), e0240005.

Chernozhukov, V., C. Hansen, and M. Spindler (2015). Post-selection and post-regularization inference in linear models with many controls and instruments. American Economic Review $105(5)$, 486-90.

Chwe, M. S.-Y. (1998). Culture, circles, and commercials: Publicity, common knowledge, and social coordination. Rationality and Society 10(1), 47-75.

Cooper, J., D. P. Green, and A. M. Wilke (2020). Reducing violence against women in uganda through video dramas: A survey experiment to illuminate causal mechanisms. In AEA Papers and Proceedings, Volume 110, pp. 615-19.

DellaVigna, S. and M. Gentzkow (2010). Persuasion: empirical evidence. Annu. Rev. Econ. 2(1), 643-669.

Dunning, T., G. Grossman, M. Humphreys, S. D. Hyde, C. McIntosh, and G. Nellis (2019). Information, Accountability, and Cumulative Learning: Lessons from Metaketa I. Cambridge University Press.

Elghossain, T., S. Bott, C. Akik, and C. M. Obermeyer (2019). Prevalence of intimate partner violence against women in the arab world: a systematic review. BMC international health and human rights 19(1), 29.

Enríquez, J., H. Larreguy, J. Marshall, and A. Simpser (2019). Online political information: Facebook ads, electoral saturation, and electoral accountability in mexico. Technical report, Working paper. 
Ferraz, C. and F. Finan (2008). Exposing corrupt politicians: the effects of brazil's publicly released audits on electoral outcomes. The Quarterly journal of economics 123(2), 703745 .

Field, E., R. Pande, N. Rigol, S. Schaner, and C. Moore (2019). On her own account: How strengthening women's financial control impacts labor supply and gender norms. Yale University Economic Growth Center Discussion Paper (1068).

Galiani, S., P. Gertler, and A. Orsola-Vidal (2012). Promoting handwashing behavior in Peru: the effect of large-scale mass-media and community level interventions. The World Bank.

Green, D. P., A. Wilke, and J. Cooper (2019). Countering violence against women at scale: A mass media experiment in rural uganda. Unpublished Manuscript, Columbia University.

Guedes, A., S. Bott, C. Garcia-Moreno, and M. Colombini (2016). Bridging the gaps: a global review of intersections of violence against women and violence against children. Global health action 9(1), 31516.

Hawcroft, C., R. Hughes, A. Shaheen, J. Usta, H. Elkadi, T. Dalton, K. Ginwalla, and G. Feder (2019). Prevalence and health outcomes of domestic violence amongst clinical populations in arab countries: a systematic review and meta-analysis. BMC public health $19(1), 315$.

Hidrobo, M. and L. Fernald (2013). Cash transfers and domestic violence. Journal of health economics 32(1), 304-319.

Humphreys, M. and J. Weinstein (2012). Policing politicians: citizen empowerment and political accountability in uganda preliminary analysis. Columbia Universities. Unpublished manuscript.

Jensen, R. and E. Oster (2009). The power of tv: Cable television and women's status in india. The Quarterly Journal of Economics 124(3), 1057-1094.

Keynejad, R. C., C. Hanlon, and L. M. Howard (2020). Psychological interventions for common mental disorders in women experiencing intimate partner violence in low-income and middle-income countries: a systematic review and meta-analysis. The Lancet Psychiatry $7(2), 173-190$.

Kim, J. C., C. H. Watts, J. R. Hargreaves, L. X. Ndhlovu, G. Phetla, L. A. Morison, J. Busza, J. D. Porter, and P. Pronyk (2007). Understanding the impact of a microfinance-based intervention on women's empowerment and the reduction of intimate partner violence in south africa. American journal of public health 97(10), 1794-1802.

Kirk, L., S. Terry, K. Lokuge, and J. L. Watterson (2017). Effectiveness of secondary and tertiary prevention for violence against women in low and low-middle income countries: a systematic review. BMC public health 17(1), 622. 
Kling, J. R., J. B. Liebman, and L. F. Katz (2007). Experimental analysis of neighborhood effects. Econometrica 75(1), 83-119.

Krug, E. G., J. A. Mercy, L. L. Dahlberg, and A. B. Zwi (2002). The world report on violence and health. The lancet 360(9339), 1083-1088.

La Ferrara, E., A. Chong, and S. Duryea (2012). Soap operas and fertility: Evidence from brazil. American Economic Journal: Applied Economics 4(4), 1-31.

Larreguy, H., J. Marshall, and J. M. Snyder (2020). Publicizing malfeasance: When the local media structure facilitates electoral accountability in mexico. The Economic Journal.

Li, Y., C. M. Marshall, H. C. Rees, A. Nunez, E. E. Ezeanolue, and J. E. Ehiri (2014). Intimate partner violence and hiv infection among women: a systematic review and metaanalysis. Journal of the international AIDS society 17(1), 18845.

Lundgren, R. and A. Amin (2015). Addressing intimate partner violence and sexual violence among adolescents: emerging evidence of effectiveness. Journal of Adolescent Health 56(1), S42-S50.

Marshall, J. (2019). Tuning in, voting out: News consumption cycles, homicides, and electoral accountability in mexico. Technical report, Working paper.

McCarthy, K. J., R. Mehta, and N. A. Haberland (2018). Gender, power, and violence: A systematic review of measures and their association with male perpetration of ipv. PLoS One 13(11), e0207091.

Melo, P., J. Messias, G. Resende, K. Garimella, J. Almeida, and F. Benevenuto (2019). Whatsapp monitor: A fact-checking system for whatsapp. In Proceedings of the International AAAI Conference on Web and Social Media, Volume 13, pp. 676-677.

Messing, J. T. and J. Thaller (2015). Intimate partner violence risk assessment: A primer for social workers. The British Journal of Social Work 45(6), 1804-1820.

Morris, S. and H. S. Shin (2002). Social value of public information. american economic review 92(5), 1521-1534.

Newman, N., R. Fletcher, A. Kalogeropoulos, and R. Nielsen (2019). Reuters Institute digital news report 2019, Volume 2019. Reuters Institute for the Study of Journalism.

Osinde, M. O., D. K. Kaye, and O. Kakaire (2011). Intimate partner violence among women with hiv infection in rural uganda: critical implications for policy and practice. $B M C$ women's health 11(1), 1-7.

Paluck, E. L. and D. P. Green (2009). Deference, dissent, and dispute resolution: An experimental intervention using mass media to change norms and behavior in rwanda. American political Science review, 622-644. 
Peterman, A., A. Potts, M. O'Donnell, K. Thompson, N. Shah, S. Oertelt-Prigione, and N. van Gelder (2020). Pandemics and violence against women and children. Center for Global Development working paper 528.

Phillips, D. Y., B. Walsh, J. W. Bullion, P. V. Reid, K. Bacon, and N. Okoro (2014). The intersection of intimate partner violence and hiv in us women: a review. Journal of the Association of Nurses in AIDS Care 25(1), S36-S49.

Pierotti, R. S. (2013). Increasing rejection of intimate partner violence: Evidence of global cultural diffusion. American Sociological Review 78(2), 240-265.

Ravallion, M., D. van de Walle, P. Dutta, and R. Murgai (2015). Empowering poor people through public information? lessons from a movie in rural india. Journal of Public Economics 132, 13-22.

Ravindran, S. and M. Shah (2020). Unintended consequences of lockdowns: Covid-19 and the shadow pandemic. Technical report, National Bureau of Economic Research.

Sable, M. R., F. Danis, D. L. Mauzy, and S. K. Gallagher (2006). Barriers to reporting sexual assault for women and men: Perspectives of college students. Journal of American College Health 55(3), 157-162.

Semahegn, A., K. Torpey, A. Manu, N. Assefa, G. Tesfaye, and A. Ankomah (2019). Are interventions focused on gender-norms effective in preventing domestic violence against women in low and lower-middle income countries? a systematic review and meta-analysis. Reproductive health 16(1), 93.

Shamu, S., N. Abrahams, C. Zarowsky, T. Shefer, and M. Temmerman (2013). Intimate partner violence during pregnancy in z imbabwe: a cross-sectional study of prevalence, predictors and associations with hiv. Tropical Medicine 86 International Health 18(6), 696-711.

Sharma, V., J. Leight, F. Verani, S. Tewolde, and N. Deyessa (2020). Effectiveness of a culturally appropriate intervention to prevent intimate partner violence and hiv transmission among men, women, and couples in rural ethiopia: Findings from a cluster-randomized controlled trial. PLoS medicine 17(8), e1003274.

Signorelli, M. C., S. Hillel, D. C. de Oliveira, B. P. A. Quintanilla, K. Hegarty, and A. Taft (2018). Voices from low-income and middle-income countries: a systematic review protocol of primary healthcare interventions within public health systems addressing intimate partner violence against women. BMJ open 8(3), e019266.

Singhal, A. and E. Rogers (2012). Entertainment-education: A communication strategy for social change. Routledge.

Suzor, N., M. Dragiewicz, B. Harris, R. Gillett, J. Burgess, and T. Van Geelen (2019). Human rights by design: The responsibilities of social media platforms to address gender-based violence online. Policy \&3 Internet 11(1), 84-103. 
Tankard, M. E. and E. L. Paluck (2016). Norm perception as a vehicle for social change. Social Issues and Policy Review 10(1), 181-211.

Wagman, J. A., R. H. Gray, J. C. Campbell, M. Thoma, A. Ndyanabo, J. Ssekasanvu, F. Nalugoda, J. Kagaayi, G. Nakigozi, D. Serwadda, et al. (2015). Effectiveness of an integrated intimate partner violence and hiv prevention intervention in rakai, uganda: analysis of an intervention in an existing cluster randomised cohort. The Lancet Global Health 3(1), e23-e33.

Wang, T., Y. Liu, Z. Li, K. Liu, Y. Xu, W. Shi, and L. Chen (2017). Prevalence of intimate partner violence (ipv) during pregnancy in china: a systematic review and meta-analysis. PloS one 12(10), e0175108.

Yount, K. M., Y. F. Cheong, R. G. Grose, and S. R. Hayford (2020). Community gender systems and a daughter's risk of female genital mutilation/cutting: Multilevel findings from egypt. Plos one 15(3), e0229917.

Yount, K. M., K. H. Krause, and S. S. Miedema (2017). Preventing gender-based violence victimization in adolescent girls in lower-income countries: Systematic review of reviews. Social Science \&3 Medicine 192, 1-13.

Yount, K. M. and L. Li (2009). Women's "justification" of domestic violence in egypt. Journal of Marriage and Family 71(5), 1125-1140.

Yount, K. M. and L. Li (2010). Domestic violence against married women in egypt. Sex roles 63(5-6), 332-347. 


\section{Appendix}

\subsection{Relationship between Key Variables at Baseline}

\subsubsection{Attitudes and Future Outlook}

Tables 5, 6, 7, 8, 9 and 10 look at associations between income, education, age, marital status, number of individuals in the household and income decline during COVID-19 on attitudinal questions. They show weakly negative relationships between finances before COVID-19 (0 struggling to make ends meet, 4 - able to save) and educational attainment (0 - no BA, 1 BA) and agreement with a range of attitudinal questions. Older women are more likely to say that husbands should provide the household income if possible and should have the final say in household decisions, but less likely to say that yelling is justified. Married women (with unmarried women defined as single, engaged, divorced, separated, and widowed) are more likely to say that husbands should ideally provide income and should have final say in family affairs, but equally likely to report prioritizing men's education or to say that yelling or hitting is justified. Women with more children and in the household (children, relatives, unrelated adults) and women who reported their family experienced any form of income decline $(4,246$ out of 5,618 , or $75 \%)$ are more likely to say that a husband should provide income, that a husband should have final say in family matters, and more likely to say that yelling or hitting is justified. The outcome questions are:

- "Husb Income": If possible, husbands should provide the household income, and women stay at home taking care of the children, elderly, and housework.

- "Husb Final Say": Husbands should usually have final say in all decisions concerning the family.

- "Prioritize Educ": If a family has to choose which children to educate, the education of men should be prioritized over the education of women.

- "Yelling Just": Husbands are sometimes justified in yelling at their wives (e.g., when the wife disobeys them).

- "Hitting Just": Husbands are sometimes justified in hitting or beating their wives (e.g., when they are under immense financial pressure). 
Table 5: Baseline Relationship btw Pre-Covid Income and Attitudes

\begin{tabular}{lccccc}
\hline \hline & \multicolumn{5}{c}{ Dependent variable: } \\
\cline { 2 - 6 } & Husb Income & Husb. Final Say & Prioritize Educ. & Yell & Hit \\
& $(1)$ & $(2)$ & $(3)$ & $(4)$ & $(5)$ \\
\hline Finances Before Covid & $-0.108^{* * *}$ & 0.023 & -0.015 & -0.018 & $-0.035^{* * *}$ \\
& $(0.018)$ & $(0.017)$ & $(0.013)$ & $(0.017)$ & $(0.008)$ \\
& & & & & \\
Constant & $2.801^{* * *}$ & $2.597^{* * *}$ & $1.469^{* * *}$ & $2.198^{* * *}$ & $1.266^{* * *}$ \\
& $(0.049)$ & $(0.047)$ & $(0.035)$ & $(0.046)$ & $(0.021)$ \\
& & & & & \\
\hline Observations & 5,618 & 5,618 & 5,618 & 5,618 & 5,618 \\
$\mathrm{R}^{2}$ & 0.006 & 0.0003 & 0.0003 & 0.0002 & 0.003 \\
Adjusted $\mathrm{R}^{2}$ & 0.006 & 0.0001 & 0.0001 & 0.00002 & 0.003 \\
\hline \hline Note: & & \multicolumn{5}{c}{${ }^{*} \mathrm{p}<0.1 ;{ }^{* *} \mathrm{p}<0.05 ;{ }^{* * *} \mathrm{p}<0.01$}
\end{tabular}

Table 6: Baseline Relationship btw Education and Attitudes

\begin{tabular}{|c|c|c|c|c|c|}
\hline & \multicolumn{5}{|c|}{ Dependent variable: } \\
\hline & $\begin{array}{l}\text { Husb Income } \\
\text { (1) }\end{array}$ & $\begin{array}{c}\text { Husb Final Say } \\
(2)\end{array}$ & $\begin{array}{c}\text { Prioritize Educ. } \\
\text { (3) }\end{array}$ & $\begin{array}{l}\text { Yell } \\
(4)\end{array}$ & $\begin{array}{l}\text { Hit } \\
(5)\end{array}$ \\
\hline Education: BA 0/1 & $\begin{array}{l}-0.035 \\
(0.029)\end{array}$ & $\begin{array}{l}0.006 \\
(0.027)\end{array}$ & $\begin{array}{c}-0.038^{*} \\
(0.020)\end{array}$ & $\begin{array}{c}-0.100^{* * *} \\
(0.027)\end{array}$ & $\begin{array}{c}-0.058^{* * *} \\
(0.013)\end{array}$ \\
\hline Constant & $\begin{array}{c}2.537^{* * *} \\
(0.022)\end{array}$ & $\begin{array}{c}2.653^{* * *} \\
(0.021)\end{array}$ & $\begin{array}{c}1.450^{* * *} \\
(0.015)\end{array}$ & $\begin{array}{c}2.208^{* * *} \\
(0.020)\end{array}$ & $\begin{array}{c}1.208^{* * *} \\
(0.009)\end{array}$ \\
\hline Observations & 5,618 & 5,618 & 5,618 & 5,618 & 5,618 \\
\hline $\mathrm{R}^{2}$ & 0.0003 & 0.00001 & 0.001 & 0.002 & 0.004 \\
\hline Adjusted $\mathrm{R}^{2}$ & 0.0001 & -0.0002 & 0.0005 & 0.002 & 0.004 \\
\hline
\end{tabular}


Table 7: Baseline Relationship between Age and Atitutdes

\begin{tabular}{lccccc}
\hline \hline & \multicolumn{5}{c}{ Dependent variable: } \\
\cline { 2 - 6 } & Husb. Income & Husb. Final Say & Prioritize Educ & Yelling Just & Hitting Just \\
& $(1)$ & $(2)$ & $(3)$ & $(4)$ & $(5)$ \\
\hline Age & $0.006^{* * *}$ & $0.007^{* * *}$ & -0.001 & $-0.010^{* * *}$ & -0.001 \\
& $(0.002)$ & $(0.001)$ & $(0.001)$ & $(0.001)$ & $(0.001)$ \\
& & & & & \\
\hline Observations & 5,618 & 5,618 & 5,618 & 5,618 & 5,618 \\
$\mathrm{R}^{2}$ & 0.003 & 0.004 & 0.0001 & 0.009 & 0.0001 \\
Adjusted $\mathrm{R}^{2}$ & 0.003 & 0.004 & -0.0001 & 0.009 & -0.0001 \\
\hline \hline Note: & \multicolumn{5}{c}{${ }^{*} \mathrm{p}<0.1 ;{ }^{* *} \mathrm{p}<0.05 ;{ }^{* * *} \mathrm{p}<0.01$}
\end{tabular}

Table 8: Baseline Relationship btw Marital Status and Attitudes

\begin{tabular}{lccccc}
\hline \hline & \multicolumn{5}{c}{ Dependent variable: } \\
\cline { 2 - 6 } & $\begin{array}{c}\text { Husb Income } \\
(1)\end{array}$ & $\begin{array}{c}\text { Husb. Final Say } \\
(2)\end{array}$ & $\begin{array}{c}\text { Prioritize Educ. } \\
(3)\end{array}$ & $\begin{array}{c}\text { Yell } \\
(4)\end{array}$ & $\begin{array}{c}\text { Hit } \\
(5)\end{array}$ \\
\hline Marital Status & $0.173^{* * *}$ & $0.362^{* * *}$ & -0.018 & -0.015 & 0.014 \\
& $(0.028)$ & $(0.027)$ & $(0.020)$ & $(0.026)$ & $(0.012)$ \\
& & & & & \\
Constant & $2.424^{* * *}$ & $2.461^{* * *}$ & $1.438^{* * *}$ & $2.159^{* * *}$ & $1.167^{* * *}$ \\
& $(0.021)$ & $(0.020)$ & $(0.015)$ & $(0.019)$ & $(0.009)$ \\
& & & & & \\
\hline Observations & 5,618 & 5,618 & 5,618 & 5,618 & 5,618 \\
$\mathrm{R}^{2}$ & 0.007 & 0.031 & 0.0001 & 0.0001 & 0.0002 \\
Adjusted $\mathrm{R}^{2}$ & 0.006 & 0.031 & -0.00003 & -0.0001 & 0.0001 \\
\hline \hline \multirow{2}{*}{ Note: } & & \multicolumn{4}{c}{${ }^{*} \mathrm{p}<0.1 ;{ }^{* *} \mathrm{p}<0.05 ;{ }^{* * *} \mathrm{p}<0.01$}
\end{tabular}


Table 9: Baseline Relationship btw Total Individuals in Household and Attitudes

\begin{tabular}{|c|c|c|c|c|c|}
\hline & \multicolumn{5}{|c|}{ Dependent variable: } \\
\hline & $\begin{array}{l}\text { Husb Income } \\
(1)\end{array}$ & $\begin{array}{l}\text { Husb Final Say } \\
(2)\end{array}$ & $\begin{array}{l}\text { Prioritize Educ. } \\
\text { (3) } \\
\end{array}$ & $\begin{array}{l}\text { Yell } \\
(4)\end{array}$ & $\begin{array}{l}\text { Hit } \\
(5) \\
\end{array}$ \\
\hline Number in Household & $\begin{array}{c}0.013^{* * *} \\
(0.005)\end{array}$ & $\begin{array}{l}0.008^{*} \\
(0.005)\end{array}$ & $\begin{array}{c}0.005 \\
(0.003)\end{array}$ & $\begin{array}{c}0.024^{* * *} \\
(0.004)\end{array}$ & $\begin{array}{c}0.009^{* * *} \\
(0.002)\end{array}$ \\
\hline Constant & $\begin{array}{c}2.467^{* * *} \\
(0.023)\end{array}$ & $\begin{array}{c}2.627^{* * *} \\
(0.022)\end{array}$ & $\begin{array}{c}1.410^{* * *} \\
(0.016)\end{array}$ & $\begin{array}{c}2.059^{* * *} \\
(0.021)\end{array}$ & $\begin{array}{c}1.139^{* * *} \\
(0.010)\end{array}$ \\
\hline Observations & 5,618 & 5,618 & 5,618 & 5,618 & 5,618 \\
\hline $\mathrm{R}^{2}$ & 0.001 & 0.001 & 0.0004 & 0.005 & 0.003 \\
\hline Adjusted $\mathrm{R}^{2}$ & 0.001 & 0.0003 & 0.0002 & 0.005 & 0.003 \\
\hline
\end{tabular}

Table 10: Baseline Relationship btw Income Decline During COVID-19 and Attitudes

\begin{tabular}{lccccc}
\hline \hline & \multicolumn{5}{c}{ Dependent variable: } \\
\cline { 2 - 6 } & Husb Income & Husb Final Say & Prioritize Educ. & Yell & Beat \\
& $(1)$ & $(2)$ & $(3)$ & $(4)$ & $(5)$ \\
\hline Covid Income Decline & $0.129^{* * *}$ & $0.061^{*}$ & 0.025 & $0.144^{* * *}$ & $0.054^{* * *}$ \\
& $(0.033)$ & $(0.032)$ & $(0.023)$ & $(0.031)$ & $(0.014)$ \\
& & & & & \\
Constant & $2.420^{* * *}$ & $2.611^{* * *}$ & $1.410^{* * *}$ & $2.042^{* * *}$ & $1.134^{* * *}$ \\
& $(0.029)$ & $(0.028)$ & $(0.020)$ & $(0.027)$ & $(0.013)$ \\
& & & & & \\
\hline Observations & 5,618 & 5,618 & 5,618 & 5,618 & 5,618 \\
$\mathrm{R}^{2}$ & 0.003 & 0.001 & 0.0002 & 0.004 & 0.002 \\
Adjusted $\mathrm{R}^{2}$ & 0.003 & 0.0005 & 0.00003 & 0.004 & 0.002 \\
\hline \hline Note: & & \multicolumn{5}{c}{${ }^{*} \mathrm{p}<0.1 ;{ }^{* *} \mathrm{p}<0.05 ;{ }^{* * *} \mathrm{p}<0.01$}
\end{tabular}


Table 11: Baseline Relationship btw Age Difference with Husband and Attitudes among Married Women

\begin{tabular}{|c|c|c|c|c|c|}
\hline & \multicolumn{5}{|c|}{ Dependent variable: } \\
\hline & $\begin{array}{l}\text { Husb Income } \\
\text { (1) }\end{array}$ & $\begin{array}{c}\text { Husb Final Say } \\
(2) \\
\end{array}$ & $\begin{array}{l}\text { Prioritize Educ. } \\
(3) \\
\end{array}$ & $\begin{array}{l}\text { Yell } \\
(4)\end{array}$ & $\begin{array}{l}\text { Hit } \\
(5)\end{array}$ \\
\hline Husband Age Diff & $\begin{array}{l}0.005^{* *} \\
(0.002)\end{array}$ & $\begin{array}{c}0.002 \\
(0.002)\end{array}$ & $\begin{array}{c}-0.0003 \\
(0.001)\end{array}$ & $\begin{array}{c}0.006^{* * *} \\
(0.002)\end{array}$ & $\begin{array}{c}-0.0002 \\
(0.001)\end{array}$ \\
\hline Constant & $\begin{array}{c}2.611^{* * *} \\
(0.020)\end{array}$ & $\begin{array}{c}2.827^{* * *} \\
(0.019)\end{array}$ & $\begin{array}{c}1.419^{* * *} \\
(0.014)\end{array}$ & $\begin{array}{c}2.159^{* * *} \\
(0.018)\end{array}$ & $\begin{array}{c}1.182^{* * *} \\
(0.009)\end{array}$ \\
\hline Observations & 3,026 & 3,026 & 3,026 & 3,026 & 3,026 \\
\hline $\mathrm{R}^{2}$ & 0.002 & 0.0004 & 0.00002 & 0.003 & 0.00002 \\
\hline Adjusted $\mathrm{R}^{2}$ & 0.002 & 0.0001 & -0.0003 & 0.003 & -0.0003 \\
\hline
\end{tabular}

Table 12: Baseline Relationship btw Husband Living Locally and Attitudes among Married Women

\begin{tabular}{|c|c|c|c|c|c|}
\hline & \multicolumn{5}{|c|}{ Dependent variable: } \\
\hline & $\begin{array}{l}\text { Husb Income } \\
\text { (1) }\end{array}$ & $\begin{array}{l}\text { Husb Final Say } \\
\qquad(2)\end{array}$ & $\begin{array}{l}\text { Prioritize Educ. } \\
\qquad(3)\end{array}$ & $\begin{array}{l}\text { Yell } \\
(4)\end{array}$ & $\begin{array}{l}\text { Hit } \\
(5)\end{array}$ \\
\hline Husb. Cohabitates & $\begin{array}{c}-0.155^{* * *} \\
(0.049)\end{array}$ & $\begin{array}{c}-0.079^{*} \\
(0.047)\end{array}$ & $\begin{array}{c}-0.092^{* * *} \\
(0.034)\end{array}$ & $\begin{array}{c}-0.110^{* *} \\
(0.045)\end{array}$ & $\begin{array}{c}-0.069^{* * *} \\
(0.022)\end{array}$ \\
\hline Constant & $\begin{array}{c}2.722^{* * *} \\
(0.044)\end{array}$ & $\begin{array}{c}2.887^{* * *} \\
(0.042)\end{array}$ & $\begin{array}{c}1.495^{* * *} \\
(0.030)\end{array}$ & $\begin{array}{c}2.234^{* * *} \\
(0.040)\end{array}$ & $\begin{array}{c}1.237^{* * *} \\
(0.020)\end{array}$ \\
\hline Observations & 3,042 & 3,042 & 3,042 & 3,042 & 3,042 \\
\hline $\mathrm{R}^{2}$ & 0.003 & 0.001 & 0.002 & 0.002 & 0.003 \\
\hline Adjusted $\mathrm{R}^{2}$ & 0.003 & 0.001 & 0.002 & 0.002 & 0.003 \\
\hline
\end{tabular}


Table 13 shows more educated women and women in more comfortable financial situations hold more negative future outlooks, measured as agreement that women will hold more equal legal rights, access to education, and economic opportunities, and will have a more equal say in their families in the future. Table 14 shows that older women hold slightly more optimistic outlooks, while married women are slightly less likely to say that in the future women will have an equal say in decisions concerning their family. Table 15 shows there is no relationship between number of individuals in household and a decline in household income during COVID-19 on future outlook.

- "Future Equal Say": In the future, women will have an equal say with their husbands in all decisions concerning the family.

- "Future Equal Rights": In the future, men and women in Egypt will have more equal legal rights, access to education, and economic opportunities. (1 - strongly disagree, 5 - strongly agree).

Table 16 shows that individuals holding views more restrictive of gender norms and more accepting of violence are more pessimistic about the future. Women who are more likely to say that hitting is justified, physical violence is justified, that husbands should provide incomes for the family, that husbands should have the final say in all matters, and that men's education should be prioritize are less likely to say that women will have an equal say in the future. We see the same relationship in Table 17 in a question geared toward rights in the future.

- "Future Equal Say": In the future, women will have an equal say with their husbands in all decisions concerning the family.

- "Future Equal Rights": In the future, men and women in Egypt will have more equal legal rights, access to education, and economic opportunities. (1 - strongly disagree, 5 - strongly agree). 
Table 13: Baseline Relationship in Education, Finances on Future Outlook

\begin{tabular}{|c|c|c|c|c|}
\hline & \multicolumn{4}{|c|}{ Dependent variable: } \\
\hline & \multicolumn{2}{|c|}{ Future Equal Say } & \multicolumn{2}{|c|}{ Future Equal Say } \\
\hline & $(1)$ & $(2)$ & (3) & (4) \\
\hline Finances Before Covid & $\begin{array}{c}-0.036^{* *} \\
(0.015)\end{array}$ & & $\begin{array}{l}-0.017 \\
(0.013)\end{array}$ & \\
\hline Education: BA 0/1 & & $\begin{array}{c}-0.042^{*} \\
(0.025)\end{array}$ & & $\begin{array}{c}-0.052^{* *} \\
(0.021)\end{array}$ \\
\hline Constant & $\begin{array}{c}4.214^{* * *} \\
(0.042)\end{array}$ & $\begin{array}{c}4.143^{* * *} \\
(0.019)\end{array}$ & $\begin{array}{c}4.341^{* * *} \\
(0.037)\end{array}$ & $\begin{array}{c}4.326^{* * *} \\
(0.016)\end{array}$ \\
\hline Observations & 5,618 & 5,618 & 5,618 & 5,618 \\
\hline $\mathrm{R}^{2}$ & 0.001 & 0.001 & 0.0003 & 0.001 \\
\hline Adjusted $R^{2}$ & 0.001 & 0.0003 & 0.0001 & 0.001 \\
\hline
\end{tabular}

Table 14: Baseline Relationship in Age, Marital Status on Future Outlook

\begin{tabular}{lcccc}
\hline \hline & \multicolumn{4}{c}{ Dependent variable: } \\
\cline { 2 - 5 } & \multicolumn{2}{c}{ Future Equal Say } & \multicolumn{2}{c}{ Future Equal Say } \\
& $(1)$ & $(2)$ & $(3)$ & $(4)$ \\
\hline Age & $0.003^{*}$ & & $0.003^{* *}$ & \\
& $(0.001)$ & & $(0.001)$ & \\
Marital Status & & & & -0.011 \\
& & $-0.045^{*}$ & & $(0.021)$ \\
Constant & $4.040^{* * *}$ & $4.144^{* * *}$ & $4.209^{* * *}$ & $4.302^{* * *}$ \\
& $(0.043)$ & $(0.018)$ & $(0.037)$ & $(0.016)$ \\
& & & & \\
\hline Observations & 5,618 & 5,618 & 5,618 & 5,618 \\
$\mathrm{R}^{2}$ & 0.001 & 0.001 & 0.001 & 0.00005 \\
Adjusted $\mathrm{R}^{2}$ & 0.0005 & 0.0004 & 0.001 & -0.0001 \\
\hline \hline Note: & \multicolumn{4}{c}{${ }^{*} \mathrm{p}<0.1 ;{ }^{* *} \mathrm{p}<0.05 ;{ }^{* * *} \mathrm{p}<0.01$}
\end{tabular}


Table 15: Baseline Relationship between Total Number of Individuals in Household, COVID19 Income Decline Status on Future Outlook

\begin{tabular}{|c|c|c|c|c|}
\hline & \multicolumn{4}{|c|}{ Dependent variable: } \\
\hline & \multicolumn{2}{|c|}{ Future Equal Say } & \multicolumn{2}{|c|}{ Future Equal Say } \\
\hline & $(1)$ & $(2)$ & $(3)$ & $(4)$ \\
\hline Number in Household & $\begin{array}{c}0.002 \\
(0.004)\end{array}$ & & $\begin{array}{c}0.001 \\
(0.004)\end{array}$ & \\
\hline Covid Income Decline & & $\begin{array}{c}0.002 \\
(0.028)\end{array}$ & & $\begin{array}{c}0.012 \\
(0.025)\end{array}$ \\
\hline Constant & $\begin{array}{c}4.112^{\text {*** }} \\
(0.020)\end{array}$ & $\begin{array}{c}4.117^{* * *} \\
(0.025)\end{array}$ & $\begin{array}{c}4.291^{* * *} \\
(0.017)\end{array}$ & $\begin{array}{c}4.287^{* * *} \\
(0.021)\end{array}$ \\
\hline Observations & 5,618 & 5,618 & 5,618 & 5,618 \\
\hline $\mathrm{R}^{2}$ & 0.00004 & 0.00000 & 0.00002 & 0.00004 \\
\hline Adjusted $\mathrm{R}^{2}$ & -0.0001 & -0.0002 & -0.0002 & -0.0001 \\
\hline
\end{tabular}


Table 16: Baseline Relationship btw. Attitudes and Outlook for Women's Say in the Future

\begin{tabular}{|c|c|c|c|c|c|}
\hline & & & endent var & & \\
\hline & & & ure Equal & & \\
\hline & $(1)$ & $(2)$ & $(3)$ & $(4)$ & $(5)$ \\
\hline Yelling Justified & $\begin{array}{c}-0.157^{* * *} \\
(0.012)\end{array}$ & & & & \\
\hline Hitting Justified & & $\begin{array}{c}-0.201^{* * *} \\
(0.026)\end{array}$ & & & \\
\hline Husb. Income & & & $\begin{array}{c}-0.140^{* * *} \\
(0.011)\end{array}$ & & \\
\hline Husb Final Say & & & & $\begin{array}{c}-0.212^{* * *} \\
(0.012)\end{array}$ & \\
\hline Prioritize Educ. Men & & & & & $\begin{array}{c}-0.129^{* * *} \\
(0.016)\end{array}$ \\
\hline Observations & 5,618 & 5,618 & 5,618 & 5,618 & 5,618 \\
\hline $\mathrm{R}^{2}$ & 0.029 & 0.010 & 0.027 & 0.056 & 0.011 \\
\hline Adjusted $\mathrm{R}^{2}$ & 0.029 & 0.010 & 0.026 & 0.056 & 0.011 \\
\hline
\end{tabular}


Table 17: Baseline Relationship btw. Attitudes and Women's Rights in the Future

\begin{tabular}{|c|c|c|c|c|c|}
\hline & & $D e$ & endent vari & le: & \\
\hline & & Fut & Ire Equal R & hts & \\
\hline & $(1)$ & $(2)$ & $(3)$ & $(4)$ & $(5)$ \\
\hline Yelling Justified & $\begin{array}{c}-0.085^{* * *} \\
(0.011)\end{array}$ & & & & \\
\hline Hitting Justified & & $\begin{array}{c}-0.185^{* * *} \\
(0.023)\end{array}$ & & & \\
\hline Husb. Income & & & $\begin{array}{c}-0.104^{* * *} \\
(0.010)\end{array}$ & & \\
\hline Husb Final Say & & & & $\begin{array}{c}-0.097^{* * *} \\
(0.010)\end{array}$ & \\
\hline Prioritize Educ. Men & & & & & $\begin{array}{c}-0.139^{* * *} \\
(0.014)\end{array}$ \\
\hline Observations & 5,618 & 5,618 & 5,618 & 5,618 & 5,618 \\
\hline $\mathrm{R}^{2}$ & 0.011 & 0.012 & 0.019 & 0.015 & 0.017 \\
\hline Adjusted $\mathrm{R}^{2}$ & 0.011 & 0.012 & 0.019 & 0.015 & 0.017 \\
\hline
\end{tabular}




\subsubsection{Knowledge}

Tables 18, 19, 20, 21 and 22 show the relationships between income, education, age, and attitudes and knowledge of online resources or organizations advising women affected by domestic violence. More educated and older women are more likely to be familiar with an organization or an online resource. More educated, affluent, and older women are more likely to know of an organization supporting women impacted by domestic violence, though not of an online resources. Married and unmarried women are equally likely to know of an online organization or resource. Individuals holding views that are more accepting of violence and less favorable toward gender equality are less likely to know online resources or organizations. Higher numbers of people in the household (children, relatives, non-related adults) and the experience of income decline in COVID-19 showed little relationship with these outcomes.

- "Know Online Resources": Which online resources do you know for women affected by domestic violence? List up to five options.

- "Know Organization": Which organizations do you know that support and advise women affected by domestic violence? List up to five options. Here, knowledge is coded as any answer other than "I don't know," but future iterations will code text answers for accuracy. 
Table 18: Baseline Relationship btw. Income, Education, Age, Marital Status and Knowledge of Organization

\begin{tabular}{|c|c|c|c|c|}
\hline & \multicolumn{4}{|c|}{ Dependent variable: } \\
\hline & \multicolumn{4}{|c|}{ Know Organization } \\
\hline & $(1)$ & $(2)$ & $(3)$ & $(4)$ \\
\hline Income pre-COVID & $\begin{array}{c}0.016^{* *} \\
(0.007)\end{array}$ & & & \\
\hline Education (BA 1/0) & & $\begin{array}{c}0.046^{* * *} \\
(0.012)\end{array}$ & & \\
\hline Age & & & $\begin{array}{c}0.003^{* * *} \\
(0.001)\end{array}$ & \\
\hline Married & & & & $\begin{array}{r}-0.008 \\
(0.012)\end{array}$ \\
\hline Constant & $\begin{array}{c}0.223^{* * *} \\
(0.020)\end{array}$ & $\begin{array}{c}0.238^{* * *} \\
(0.009)\end{array}$ & $\begin{array}{c}0.168^{* * *} \\
(0.021)\end{array}$ & $\begin{array}{c}0.268^{* * *} \\
(0.009)\end{array}$ \\
\hline Observations & 5,618 & 5,618 & 5,618 & 5,618 \\
\hline $\mathrm{R}^{2}$ & 0.001 & 0.003 & 0.004 & 0.0001 \\
\hline Adjusted $\mathrm{R}^{2}$ & 0.001 & 0.002 & 0.004 & -0.0001 \\
\hline
\end{tabular}


Table 19: Baseline Relationship btw. Income, Education, Age, Marital Status and Knowledge of Online Resource

\begin{tabular}{|c|c|c|c|c|}
\hline & \multicolumn{4}{|c|}{ Dependent variable: } \\
\hline & \multicolumn{4}{|c|}{ Know Online } \\
\hline & $(1)$ & $(2)$ & $(3)$ & $(4)$ \\
\hline Income pre-COVID & $\begin{array}{c}0.003 \\
(0.008)\end{array}$ & & & \\
\hline Education (BA 1/0) & & $\begin{array}{c}0.023^{*} \\
(0.012)\end{array}$ & & \\
\hline Age & & & $\begin{array}{c}0.002^{* * *} \\
(0.001)\end{array}$ & \\
\hline Married & & & & $\begin{array}{c}0.005 \\
(0.012)\end{array}$ \\
\hline Constant & $\begin{array}{c}0.289^{* * *} \\
(0.021)\end{array}$ & $\begin{array}{c}0.283^{* * *} \\
(0.009)\end{array}$ & $\begin{array}{c}0.228^{* * *} \\
(0.021)\end{array}$ & $\begin{array}{c}0.293^{* * *} \\
(0.009)\end{array}$ \\
\hline Observations & 5,618 & 5,618 & 5,618 & 5,618 \\
\hline $\mathrm{R}^{2}$ & 0.00002 & 0.001 & 0.002 & 0.00003 \\
\hline Adjusted $\mathrm{R}^{2}$ & -0.0002 & 0.0005 & 0.002 & -0.0001 \\
\hline
\end{tabular}


Table 20: Baseline Relationship btw. Total in Household, COVID-19 Income Decline on Knowledge of Organization or Online Resource

\begin{tabular}{|c|c|c|c|c|}
\hline & \multicolumn{4}{|c|}{ Dependent variable: } \\
\hline & \multicolumn{2}{|c|}{ Know Organization } & \multicolumn{2}{|c|}{ know_org_num } \\
\hline & $(1)$ & $(2)$ & $(3)$ & $(4)$ \\
\hline Number in Household & $\begin{array}{l}-0.001 \\
(0.002)\end{array}$ & & $\begin{array}{c}-0.004^{*} \\
(0.002)\end{array}$ & \\
\hline Covid Income Decline & & $\begin{array}{c}0.021 \\
(0.014)\end{array}$ & & $\begin{array}{c}-0.004 \\
(0.014)\end{array}$ \\
\hline Constant & $\begin{array}{c}0.299^{* * *} \\
(0.010)\end{array}$ & $\begin{array}{c}0.280^{* * *} \\
(0.012)\end{array}$ & $\begin{array}{c}0.279^{* * *} \\
(0.010)\end{array}$ & $\begin{array}{c}0.267^{* * *} \\
(0.012)\end{array}$ \\
\hline Observations & 5,618 & 5,618 & 5,618 & 5,618 \\
\hline $\mathrm{R}^{2}$ & 0.00003 & 0.0004 & 0.001 & 0.00001 \\
\hline Adjusted $\mathrm{R}^{2}$ & -0.0002 & 0.0002 & 0.0005 & -0.0002 \\
\hline
\end{tabular}


Table 21: Baseline Relationship btw. Attitudes and Knowledge of Online Resources

\begin{tabular}{|c|c|c|c|c|c|}
\hline & \multicolumn{5}{|c|}{ Dependent variable: } \\
\hline & \multicolumn{5}{|c|}{ Know Online Resources } \\
\hline & (1) & $(2)$ & (3) & (4) & (5) \\
\hline Yelling Justified & $\begin{array}{c}-0.025^{* * *} \\
(0.006)\end{array}$ & & & & \\
\hline Hitting Justified & & $\begin{array}{c}0.017 \\
(0.013)\end{array}$ & & & \\
\hline Husb. Income & & & $\begin{array}{c}-0.027^{* * *} \\
(0.006)\end{array}$ & & \\
\hline Husb Final Say & & & & $\begin{array}{c}-0.019^{* * *} \\
(0.006)\end{array}$ & \\
\hline Prioritize Educ. Men & & & & & $\begin{array}{l}-0.005 \\
(0.008)\end{array}$ \\
\hline Constant & $\begin{array}{c}0.350^{* * *} \\
(0.015)\end{array}$ & $\begin{array}{c}0.275^{* * *} \\
(0.017)\end{array}$ & $\begin{array}{c}0.365^{* * *} \\
(0.016)\end{array}$ & $\begin{array}{c}0.346^{* * *} \\
(0.017)\end{array}$ & $\begin{array}{c}0.304^{* * *} \\
(0.013)\end{array}$ \\
\hline Observations & 5,618 & 5,618 & 5,618 & 5,618 & 5,618 \\
\hline $\mathrm{R}^{2}$ & 0.003 & 0.0003 & 0.004 & 0.002 & 0.0001 \\
\hline Adjusted $\mathrm{R}^{2}$ & 0.003 & 0.0001 & 0.004 & 0.002 & -0.0001 \\
\hline
\end{tabular}


Table 22: Baseline Relationship btw. Attitudes and Knowledge of Organization

\begin{tabular}{lccccc}
\hline \hline & \multicolumn{5}{c}{ Dependent variable: } \\
\cline { 2 - 5 } & \multicolumn{5}{c}{ Know Organization } \\
& $(1)$ & $(2)$ & $(3)$ & $(4)$ & $(5)$ \\
\hline Yelling Justified & $-0.028^{* * *}$ & & &
\end{tabular}

Hitting Justified $\quad-0.001$

$(0.013)$

Husb. Income

$-0.036^{* * *}$

$(0.006)$

Husb Final Say

$-0.017^{* * *}$

(0.006)

Prioritize Educ. Men

$-0.029^{* * *}$

$(0.008)$

Constant

$0.323^{* * *}$

$0.265^{* * *}$

$0.354^{* * *}$

$0.309^{* * *}$

$0.305^{* * *}$

(0.014)

(0.016)

(0.015)

(0.016)

(0.013)

\begin{tabular}{lccccc}
\hline Observations & 5,618 & 5,618 & 5,618 & 5,618 & 5,618 \\
$\mathrm{R}^{2}$ & 0.004 & 0.00000 & 0.007 & 0.002 & 0.002 \\
Adjusted $\mathrm{R}^{2}$ & 0.004 & -0.0002 & 0.007 & 0.001 & 0.002 \\
\hline \hline
\end{tabular}

Note:

${ }^{*} \mathrm{p}<0.1 ;{ }^{* *} \mathrm{p}<0.05 ;{ }^{* * *} \mathrm{p}<0.01$ 


\subsubsection{Hypothetical Behavior}

Tables 23, 24 and 25 show that more educated women are more likely and older women less likely to report to authorities, and both are equally likely to look for resources or contact an online organization in a scenario where a friend has been affected by domestic violence. Married women are less likely to contact authorities, less likely to look for online resources, and less likely to contact an organization. Income has no significant on these hypothetical behaviors. Women with more crowding in the household (total children, relatives, and unrelated adults) are less likely to report to authorities and slightly less likely to contact an organization in a domestic violence scenario, while women whose households have experienced income decline in the COVID-19 pandemic are similarly less likely to contact authorities. Tables 26, 27 and 28 show negative relationships between attitudes more accepting of violence and gender inequality and willingness to contact authorities, look for online resources, or contact an organization in a scenario where a friend has been affected by domestic violence.

- "Report Authorities", "Contact Org", "Look for Online Resources": Suppose that a friend tells you that she has been affected by domestic violence and asks you for your advice. How likely would you be to recommend her to: Report to designated authorities/contact an organization supporting women/look for online resources? (1 Unlikely, 5 - Very likely) 
Table 23: Baseline Relationship btw. Income, Age, Education, Marital Status and Reporting to Authorities in DV Scenario

\begin{tabular}{|c|c|c|c|c|c|c|}
\hline & \multicolumn{6}{|c|}{ Dependent variable: } \\
\hline & \multicolumn{6}{|c|}{ Report Authorities } \\
\hline & $(1)$ & $(2)$ & $(3)$ & $(4)$ & $(5)$ & $(6)$ \\
\hline Income & $\begin{array}{c}0.003 \\
(0.022)\end{array}$ & & & & & \\
\hline Education (BA 0/1) & & $\begin{array}{c}0.083^{* *} \\
(0.036)\end{array}$ & & & & \\
\hline Age (Years) & & & $\begin{array}{c}-0.019^{* * *} \\
(0.002)\end{array}$ & & & \\
\hline Married & & & & $\begin{array}{c}-0.437^{* * *} \\
(0.035)\end{array}$ & & \\
\hline \# in Household & & & & & $\begin{array}{c}-0.025^{* * *} \\
(0.006)\end{array}$ & \\
\hline COVID Inc. Decline & & & & & & $\begin{array}{c}-0.090^{* *} \\
(0.041)\end{array}$ \\
\hline Constant & $\begin{array}{c}2.618^{* * *} \\
(0.061)\end{array}$ & $\begin{array}{c}2.578^{* * *} \\
(0.027)\end{array}$ & $\begin{array}{c}3.207^{* * *} \\
(0.062)\end{array}$ & $\begin{array}{c}2.862^{* * *} \\
(0.026)\end{array}$ & $\begin{array}{c}2.723^{* * *} \\
(0.029)\end{array}$ & $\begin{array}{c}2.693^{* * *} \\
(0.036)\end{array}$ \\
\hline Observations & 5,618 & 5,618 & 5,618 & 5,618 & 5,618 & 5,618 \\
\hline $\mathrm{R}^{2}$ & 0.00000 & 0.001 & 0.017 & 0.027 & 0.003 & 0.001 \\
\hline Adjusted $\mathrm{R}^{2}$ & -0.0002 & 0.001 & 0.017 & 0.027 & 0.003 & 0.001 \\
\hline
\end{tabular}


Table 24: Baseline Relationship btw. Income, Age, Education, Marital Status, Total in Household and COVID-19 Income Decline and Looking Online in DV Scenario

\begin{tabular}{|c|c|c|c|c|c|c|}
\hline & \multicolumn{6}{|c|}{ Dependent variable: } \\
\hline & \multicolumn{6}{|c|}{ Report Authorities } \\
\hline & $(1)$ & $(2)$ & $(3)$ & $(4)$ & $(5)$ & $(6)$ \\
\hline Income & $\begin{array}{c}0.028 \\
(0.021)\end{array}$ & & & & & \\
\hline Education (BA 0/1) & & $\begin{array}{l}-0.015 \\
(0.034)\end{array}$ & & & & \\
\hline Age (Years) & & & $\begin{array}{c}-0.004^{* *} \\
(0.002)\end{array}$ & & & \\
\hline Married & & & & $\begin{array}{c}-0.181^{* * *} \\
(0.033)\end{array}$ & & \\
\hline \# in Household & & & & & $\begin{array}{c}-0.0003 \\
(0.006)\end{array}$ & \\
\hline COVID Inc. Decline & & & & & & $\begin{array}{l}-0.026 \\
(0.039)\end{array}$ \\
\hline Constant & $\begin{array}{c}2.553^{* * *} \\
(0.058)\end{array}$ & $\begin{array}{c}2.635^{* * *} \\
(0.025)\end{array}$ & $\begin{array}{c}2.764^{* * *} \\
(0.059)\end{array}$ & $\begin{array}{c}2.724^{* * *} \\
(0.025)\end{array}$ & $\begin{array}{c}2.627^{* * *} \\
(0.027)\end{array}$ & $\begin{array}{c}2.646^{* * *} \\
(0.034)\end{array}$ \\
\hline Observations & 5,618 & 5,618 & 5,618 & 5,618 & 5,618 & 5,618 \\
\hline $\mathrm{R}^{2}$ & 0.0003 & 0.00004 & 0.001 & 0.005 & 0.00000 & 0.0001 \\
\hline Adjusted $\mathrm{R}^{2}$ & 0.0001 & -0.0001 & 0.001 & 0.005 & -0.0002 & -0.0001 \\
\hline
\end{tabular}


Table 25: Baseline Relationship btw. Income, Age, Education, Marital Status, Total in Household and COVID-19 Income Decline and Contacting Org in DV Scenario

\begin{tabular}{|c|c|c|c|c|c|c|}
\hline & \multicolumn{6}{|c|}{ Dependent variable: } \\
\hline & \multicolumn{6}{|c|}{ Report Authorities } \\
\hline & $(1)$ & $(2)$ & $(3)$ & $(4)$ & $(5)$ & $(6)$ \\
\hline Income & $\begin{array}{c}0.038^{*} \\
(0.021)\end{array}$ & & & & & \\
\hline Education (BA 0/1) & & $\begin{array}{c}0.024 \\
(0.033)\end{array}$ & & & & \\
\hline Age (Years) & & & $\begin{array}{l}-0.001 \\
(0.002)\end{array}$ & & & \\
\hline Married & & & & $\begin{array}{c}-0.150^{* * *} \\
(0.033)\end{array}$ & & \\
\hline \# in Household & & & & & $\begin{array}{c}-0.009^{*} \\
(0.006)\end{array}$ & \\
\hline COVID Inc. Decline & & & & & & $\begin{array}{c}0.004 \\
(0.039)\end{array}$ \\
\hline Constant & $\begin{array}{c}3.217^{* * *} \\
(0.057)\end{array}$ & $\begin{array}{c}3.302^{* * *} \\
(0.025)\end{array}$ & $\begin{array}{c}3.356^{* * *} \\
(0.058)\end{array}$ & $\begin{array}{c}3.397^{* * *} \\
(0.024)\end{array}$ & $\begin{array}{c}3.352^{* * *} \\
(0.027)\end{array}$ & $\begin{array}{c}3.313^{* * *} \\
(0.034)\end{array}$ \\
\hline Observations & 5,618 & 5,618 & 5,618 & 5,618 & 5,618 & 5,618 \\
\hline $\mathrm{R}^{2}$ & 0.001 & 0.0001 & 0.0001 & 0.004 & 0.001 & 0.00000 \\
\hline Adjusted $\mathrm{R}^{2}$ & 0.0004 & -0.0001 & -0.0001 & 0.003 & 0.0003 & -0.0002 \\
\hline
\end{tabular}


Table 26: Baseline Relationship: Attitudes and Likelihood to Report to Authorities

\begin{tabular}{|c|c|c|c|c|c|}
\hline & \multicolumn{5}{|c|}{ Dependent variable: } \\
\hline & \multicolumn{5}{|c|}{ Report Authorities } \\
\hline & $(1)$ & $(2)$ & $(3)$ & (4) & $(5)$ \\
\hline Yelling Justified & $\begin{array}{c}-0.224^{* * *} \\
(0.018)\end{array}$ & & & & \\
\hline Hitting Justified & & $\begin{array}{c}-0.182^{* * *} \\
(0.038)\end{array}$ & & & \\
\hline Husb. Income & & & $\begin{array}{c}-0.155^{* * *} \\
(0.016)\end{array}$ & & \\
\hline Husb Final Say & & & & $\begin{array}{c}-0.222^{* * *} \\
(0.017)\end{array}$ & \\
\hline Prioritize Educ. Men & & & & & $\begin{array}{c}-0.118^{* * *} \\
(0.024)\end{array}$ \\
\hline Constant & $\begin{array}{c}3.107^{* * *} \\
(0.042)\end{array}$ & $\begin{array}{c}2.838^{* * *} \\
(0.048)\end{array}$ & $\begin{array}{c}3.016^{* * *} \\
(0.045)\end{array}$ & $\begin{array}{c}3.214^{* * *} \\
(0.049)\end{array}$ & $\begin{array}{c}2.794^{* * *} \\
(0.038)\end{array}$ \\
\hline Observations & 5,618 & 5,618 & 5,618 & 5,618 & 5,618 \\
\hline $\mathrm{R}^{2}$ & 0.028 & 0.004 & 0.016 & 0.029 & 0.004 \\
\hline Adjusted $\mathrm{R}^{2}$ & 0.028 & 0.004 & 0.015 & 0.029 & 0.004 \\
\hline
\end{tabular}


Table 27: Baseline Relationship btw. Attitudes and Likelihood Looking for Resources

\begin{tabular}{|c|c|c|c|c|c|}
\hline & & & ndent vari & & \\
\hline & & & $\mathrm{k}$ Online $\mathrm{I}$ & & \\
\hline & $(1)$ & $(2)$ & (3) & (4) & $(5)$ \\
\hline Yelling Justified & $\begin{array}{c}-0.096^{* * *} \\
(0.017)\end{array}$ & & & & \\
\hline Hitting Justified & & $\begin{array}{c}0.017 \\
(0.036)\end{array}$ & & & \\
\hline Husb. Income & & & $\begin{array}{c}-0.080^{* * *} \\
(0.016)\end{array}$ & & \\
\hline Husb Final Say & & & & $\begin{array}{c}-0.088^{* * *} \\
(0.016)\end{array}$ & \\
\hline Prioritize Educ. Men & & & & & $\begin{array}{l}-0.008 \\
(0.022)\end{array}$ \\
\hline Constant & $\begin{array}{c}2.834^{* * *} \\
(0.040)\end{array}$ & $\begin{array}{c}2.606^{* * *} \\
(0.045)\end{array}$ & $\begin{array}{c}2.828^{* * *} \\
(0.043)\end{array}$ & $\begin{array}{c}2.861^{* * *} \\
(0.047)\end{array}$ & $\begin{array}{c}2.637^{* * *} \\
(0.036)\end{array}$ \\
\hline Observations & 5,618 & 5,618 & 5,618 & 5,618 & 5,618 \\
\hline $\mathrm{R}^{2}$ & 0.006 & 0.00004 & 0.005 & 0.005 & 0.00002 \\
\hline Adjusted $\mathrm{R}^{2}$ & 0.006 & -0.0001 & 0.004 & 0.005 & -0.0002 \\
\hline
\end{tabular}


Table 28: Baseline Relationship btw. Attitudes and Likelihood Contacting Org

\begin{tabular}{|c|c|c|c|c|c|}
\hline & \multicolumn{5}{|c|}{ Dependent variable: } \\
\hline & \multicolumn{5}{|c|}{ Contact an Organization } \\
\hline & (1) & (2) & (3) & (4) & (5) \\
\hline Yelling Justified & $\begin{array}{c}-0.125^{* * *} \\
(0.017)\end{array}$ & & & & \\
\hline Hitting Justified & & $\begin{array}{c}-0.122^{* * *} \\
(0.036)\end{array}$ & & & \\
\hline Husb. Income & & & $\begin{array}{c}-0.116^{* * *} \\
(0.016)\end{array}$ & & \\
\hline Husb Final Say & & & & $\begin{array}{c}-0.118^{* * *} \\
(0.016)\end{array}$ & \\
\hline Prioritize Educ. Men & & & & & $\begin{array}{c}-0.096^{* * *} \\
(0.022)\end{array}$ \\
\hline Constant & $\begin{array}{c}3.585^{* * *} \\
(0.040)\end{array}$ & $\begin{array}{c}3.459^{* * *} \\
(0.045)\end{array}$ & $\begin{array}{c}3.607^{* * *} \\
(0.042)\end{array}$ & $\begin{array}{c}3.631^{* * *} \\
(0.046)\end{array}$ & $\begin{array}{c}3.453^{* * *} \\
(0.036)\end{array}$ \\
\hline Observations & 5,618 & 5,618 & 5,618 & 5,618 & 5,618 \\
\hline $\mathrm{R}^{2}$ & 0.010 & 0.002 & 0.010 & 0.009 & 0.003 \\
\hline Adjusted $R^{2}$ & 0.010 & 0.002 & 0.010 & 0.009 & 0.003 \\
\hline
\end{tabular}




\subsubsection{Reported Experience of Violence at Baseline}

Tables 29, 30, 31, 32 and 33 show the relationships between educational attainment, preCOVID finances, age, marital status, totals in the household, COVID-19 income decline and attitudes and reports of witnessing or experiencing yelling or hitting before COVID-19. While older women and women in more challenging economic conditions reported witnessing or experiencing higher rates of yelling or violence, married women reported witnessing or experiencing lower levels of violence. Women with attitudes more accepting of violence and less in favor of gender equality report experiencing lower levels of violence in the month before COVID-19. Individuals with higher numbers in the household are slightly more likely to report experiencing or witnessing yelling and hitting before the outbreak of COVID-19 outbreak, while those who subsequently witnessed an income decline are significantly more likely to do so.

- "Report Yelling": In the month BEFORE the COVID-19 pandemic, how frequently did you hear of someone being yelled at by a man or have you yourself experienced this? (Never - 0; Very often - 5)

- "Report Hitting": In the month BEFORE the beginning of the COVID-19 pandemic, how frequently did you hear of someone being hit by a man or have you yourself experienced this? (Never - 0; Very often - 5)

Table 29: Baseline Relationship btw. Education, Finances and Reported Violence

\begin{tabular}{|c|c|c|c|c|}
\hline & \multicolumn{4}{|c|}{ Dependent variable: } \\
\hline & \multicolumn{2}{|c|}{ Report Yelling } & \multicolumn{2}{|c|}{ Report Hitting } \\
\hline & (1) & (2) & (3) & (4) \\
\hline Finances before COVID & $\begin{array}{c}-0.123^{* * *} \\
(0.019)\end{array}$ & & $\begin{array}{c}-0.134^{* * *} \\
(0.021)\end{array}$ & \\
\hline Educ: BA or Above & & $\begin{array}{l}-0.003 \\
(0.031)\end{array}$ & & $\begin{array}{l}-0.047 \\
(0.034)\end{array}$ \\
\hline Constant & $\begin{array}{c}4.005^{* * *} \\
(0.053)\end{array}$ & $\begin{array}{c}3.685^{* * *} \\
(0.024)\end{array}$ & $\begin{array}{c}3.705^{* * *} \\
(0.059)\end{array}$ & $\begin{array}{c}3.380^{* * *} \\
(0.026)\end{array}$ \\
\hline Observations & 5,618 & 5,618 & 5,618 & 5,618 \\
\hline $\mathrm{R}^{2}$ & 0.007 & 0.00000 & 0.007 & 0.0003 \\
\hline Adjusted $\mathrm{R}^{2}$ & 0.007 & -0.0002 & 0.007 & 0.0001 \\
\hline
\end{tabular}


Table 30: Baseline Relationship btw. Age, Marital Status and Reported Violence

\begin{tabular}{|c|c|c|c|c|}
\hline & \multicolumn{4}{|c|}{ Dependent variable: } \\
\hline & \multicolumn{2}{|c|}{ Report Yelling } & \multicolumn{2}{|c|}{ Report Hitting } \\
\hline & $(1)$ & $(2)$ & $(3)$ & $(4)$ \\
\hline Age & $\begin{array}{c}-0.008^{* * *} \\
(0.002)\end{array}$ & & $\begin{array}{c}-0.016^{* * *} \\
(0.002)\end{array}$ & \\
\hline Married & & $\begin{array}{c}-0.264^{* * *} \\
(0.031)\end{array}$ & & $\begin{array}{c}-0.382^{* * *} \\
(0.034)\end{array}$ \\
\hline Constant & $\begin{array}{c}3.924^{* * *} \\
(0.054)\end{array}$ & $\begin{array}{c}3.826^{* * *} \\
(0.023)\end{array}$ & $\begin{array}{c}3.863^{* * *} \\
(0.060)\end{array}$ & $\begin{array}{c}3.560^{* * *} \\
(0.025)\end{array}$ \\
\hline Observations & 5,618 & 5,618 & 5,618 & 5,618 \\
\hline $\mathrm{R}^{2}$ & 0.004 & 0.013 & 0.014 & 0.022 \\
\hline Adjusted $\mathrm{R}^{2}$ & 0.004 & 0.013 & 0.014 & 0.022 \\
\hline
\end{tabular}

Table 31: Baseline Relationship btw. Number in Household, COVID-19 Income Decline and Reported Violence

\begin{tabular}{|c|c|c|c|c|}
\hline & \multicolumn{4}{|c|}{ Dependent variable: } \\
\hline & \multicolumn{2}{|c|}{ Report Yelling } & \multicolumn{2}{|c|}{ Report Hitting } \\
\hline & (1) & $(2)$ & $(3)$ & (4) \\
\hline in Household & $\begin{array}{c}0.009^{*} \\
(0.005)\end{array}$ & & $\begin{array}{c}0.011^{*} \\
(0.006)\end{array}$ & \\
\hline Covid Inc. Deceline & & $\begin{array}{c}0.156^{* * *} \\
(0.036)\end{array}$ & & $\begin{array}{c}0.226^{* * *} \\
(0.040)\end{array}$ \\
\hline Constant & $\begin{array}{c}3.648^{* * *} \\
(0.025)\end{array}$ & $\begin{array}{c}3.566^{* * *} \\
(0.031)\end{array}$ & $\begin{array}{c}3.311^{* * *} \\
(0.028)\end{array}$ & $\begin{array}{c}3.182^{* * *} \\
(0.034)\end{array}$ \\
\hline Observations & 5,618 & 5,618 & 5,618 & 5,618 \\
\hline $\mathrm{R}^{2}$ & 0.001 & 0.003 & 0.001 & 0.006 \\
\hline Adjusted $\mathrm{R}^{2}$ & 0.0004 & 0.003 & 0.0005 & 0.006 \\
\hline
\end{tabular}


Table 32: Baseline Relationship btw. Attitudes and Reported Experience of or Witness Yelling

\begin{tabular}{|c|c|c|c|c|c|}
\hline & \multicolumn{5}{|c|}{ Dependent variable: } \\
\hline & \multicolumn{5}{|c|}{ Report Yelling } \\
\hline & (1) & $(2)$ & $(3)$ & $(4)$ & $(5)$ \\
\hline Yelling Justified & $\begin{array}{c}-0.055^{* * *} \\
(0.016)\end{array}$ & & & & \\
\hline Hitting Justified & & $\begin{array}{c}-0.179^{* * *} \\
(0.033)\end{array}$ & & & \\
\hline Husb. Income & & & $\begin{array}{c}-0.029^{* *} \\
(0.015)\end{array}$ & & \\
\hline Husb Final Say & & & & $\begin{array}{c}-0.107^{* * *} \\
(0.015)\end{array}$ & \\
\hline Prioritize Educ. Men & & & & & $\begin{array}{c}-0.036^{*} \\
(0.021)\end{array}$ \\
\hline Constant & $\begin{array}{c}3.802^{* * *} \\
(0.037)\end{array}$ & $\begin{array}{c}3.893^{* * *} \\
(0.042)\end{array}$ & $\begin{array}{c}3.755^{\text {*** }} \\
(0.040)\end{array}$ & $\begin{array}{c}3.967^{* * *} \\
(0.043)\end{array}$ & $\begin{array}{c}3.735^{* * *} \\
(0.033)\end{array}$ \\
\hline Observations & 5,618 & 5,618 & 5,618 & 5,618 & 5,618 \\
\hline $\mathrm{R}^{2}$ & 0.002 & 0.005 & 0.001 & 0.009 & 0.001 \\
\hline Adjusted $\mathrm{R}^{2}$ & 0.002 & 0.005 & 0.001 & 0.009 & 0.0004 \\
\hline
\end{tabular}


Table 33: Baseline Relationship btw. Attitudes and Reported Experience of or Witness Hitting

\begin{tabular}{|c|c|c|c|c|c|}
\hline & \multicolumn{5}{|c|}{ Dependent variable: } \\
\hline & \multicolumn{5}{|c|}{ Report Hitting } \\
\hline & (1) & $(2)$ & (3) & (4) & (5) \\
\hline Yelling Justified & $\begin{array}{c}-0.070^{* * *} \\
(0.017)\end{array}$ & & & & \\
\hline Hitting Justified & & $\begin{array}{c}-0.125^{* * *} \\
(0.037)\end{array}$ & & & \\
\hline Husb. Income & & & $\begin{array}{l}-0.019 \\
(0.016)\end{array}$ & & \\
\hline Husb Final Say & & & & $\begin{array}{c}-0.127^{* * *} \\
(0.017)\end{array}$ & \\
\hline Prioritize Educ. Men & & & & & $\begin{array}{l}-0.037 \\
(0.023)\end{array}$ \\
\hline Constant & $\begin{array}{c}3.503^{* * *} \\
(0.041)\end{array}$ & $\begin{array}{c}3.499^{* * *} \\
(0.046)\end{array}$ & $\begin{array}{c}3.401^{* * *} \\
(0.044)\end{array}$ & $\begin{array}{c}3.690^{* * *} \\
(0.047)\end{array}$ & $\begin{array}{c}3.406^{* * *} \\
(0.037)\end{array}$ \\
\hline Observations & 5,618 & 5,618 & 5,618 & 5,618 & 5,618 \\
\hline $\mathrm{R}^{2}$ & 0.003 & 0.002 & 0.0003 & 0.010 & 0.0005 \\
\hline Adjusted $\mathrm{R}^{2}$ & 0.003 & 0.002 & 0.0001 & 0.010 & 0.0003 \\
\hline
\end{tabular}


7.2 Video Messages and Television Content 


\begin{tabular}{|c|c|c|}
\hline Ep. & Title & Content \\
\hline 1 & $\begin{array}{l}\text { What is sexual harass- } \\
\text { ment and what is its } \\
\text { penalty? }\end{array}$ & $\begin{array}{l}\text { Pervasiveness of sexual harassment; definition; harassment in } \\
\text { public, on streets or in stores; men's role in harassment; legal } \\
\text { rights; interfering when you witness harassment. }\end{array}$ \\
\hline 2 & $\begin{array}{l}\text { Sexual harassment of } \\
\text { children and how to } \\
\text { protect them? }\end{array}$ & $\begin{array}{l}\text { Sexual harassment of children; protecting, supporting, \& believ- } \\
\text { ing children; boundaries; contact ECWR. }\end{array}$ \\
\hline 3 & $\begin{array}{l}\text { Are women's clothes } \\
\text { the cause of sexual ha- } \\
\text { rassment? }\end{array}$ & $\begin{array}{l}\text { Sexual harassment; justifiability of sexual harassment; research } \\
\text { on when it occurs; personal experiences; harassment and veiling, } \\
\text { the Niqab; supporting victims. }\end{array}$ \\
\hline 4 & $\begin{array}{l}\text { FGC and how to stop } \\
\text { it? }\end{array}$ & $\begin{array}{l}\text { FGC; negative health effects; absence of relationship with reli- } \\
\text { gion; criminality; doctors role; contact ECWR. }\end{array}$ \\
\hline 5 & $\begin{array}{l}\text { Impact of COVID-19 } \\
\text { on increasing domestic } \\
\text { violence }\end{array}$ & $\begin{array}{l}\text { COVID-19 \& DV; safety in the home; justifiability of violence; } \\
\text { violence's harm to relationships; cycles of violence; supporting } \\
\text { victims; contact ECWR. }\end{array}$ \\
\hline 6 & $\begin{array}{l}\text { Rape crimes and how } \\
\text { to fight them }\end{array}$ & $\begin{array}{l}\text { COVID-19 \& social issues; anxiety; spread of violence \& rape in } \\
\text { public spaces; female clothing; how to report to police; gaining } \\
\text { justice; family support; psychological effects; contact ECWR. }\end{array}$ \\
\hline 7 & $\begin{array}{l}\text { The difference be- } \\
\text { tween divorce and } \\
\text { Khul' and when to } \\
\text { choose either? }\end{array}$ & $\begin{array}{l}\text { COVID-19 rise in DV; rise in questions re: divorce and Khul'; dif- } \\
\text { ference between two; legal rights; Egyptian law; contact ECWR. }\end{array}$ \\
\hline 8 & $\begin{array}{l}\text { The importance of } \\
\text { work and how to } \\
\text { balance between work } \\
\text { and home? }\end{array}$ & $\begin{array}{l}\text { Absence of conflict between work and home; safety via financial } \\
\text { security; work's benefit to social relations and esteem; work and } \\
\text { tensions with a husband or family; work as a safety net; contact } \\
\text { ECWR. }\end{array}$ \\
\hline 9 & $\begin{array}{l}\text { The negative effects of } \\
\text { Covid-19 on women's } \\
\text { work }\end{array}$ & $\begin{array}{l}\text { COVID-19 and labor market; schools; working remotely; com- } \\
\text { bating sexual harassment at the workplace; inappropriate star- } \\
\text { ing; sexual harassment as a crime; contact ECWR. }\end{array}$ \\
\hline 10 & $\begin{array}{l}\text { How to deal with } \\
\text { workplace harass- } \\
\text { ment? }\end{array}$ & $\begin{array}{l}\text { Definition; lack of justifiability; online harassment; criminality; } \\
\text { intervening in a case of harassment; expressing opinions; creating } \\
\text { a safe workplace; contact ECWR. }\end{array}$ \\
\hline 11 & $\begin{array}{l}\text { How to act if you saw } \\
\text { someone harassing a } \\
\text { colleague at work? }\end{array}$ & $\begin{array}{l}\text { COVID-19 \& changes in workplace; work environment; interven- } \\
\text { ing in harassment; helping a colleague; importance of speaking } \\
\text { up; assuring privacy; contact ECWR. }\end{array}$ \\
\hline 12 & $\begin{array}{l}\text { Dealing with work- } \\
\text { place harassment for } \\
\text { new employees }\end{array}$ & $\begin{array}{l}\text { Workplace harassment; seeking training as a new employee; ex- } \\
\text { pectations and boundaries; saying no. }\end{array}$ \\
\hline 13 & $\begin{array}{l}\text { How can men stand } \\
\text { against } \quad \text { violence } \\
\text { against women? }\end{array}$ & $\begin{array}{l}\text { Need for men's support; COVID-19 and rise of ECWR com- } \\
\text { plaints; men's role in intervening; men's role in regulating anger; } \\
\text { no justifiability of anger or violence; blame on women; men } \\
\text { standing against violence; contact ECWR. }\end{array}$ \\
\hline
\end{tabular}

Table 34: Content of Hosted Videos Delivered via Message 


\begin{tabular}{|c|c|c|}
\hline Ep. & Title & Content \\
\hline 1 & $\begin{array}{l}\text { Statement of the Egyp- } \\
\text { tian Public Prosecutor }\end{array}$ & $\begin{array}{l}\text { Female Genital Cutting (FGC); one family's experience; } \\
\text { a family's criminal responsibility. }\end{array}$ \\
\hline 2 & $\begin{array}{l}\text { Horrible Stories from } \\
\text { Medical Clinics }\end{array}$ & $\begin{array}{l}\text { FGB; doctors' role in limiting FGC; FGC's lack of health } \\
\text { benefits; Social relationships in COVID-19. }\end{array}$ \\
\hline 3 & $\begin{array}{l}\text { Rape and Sexual Har- } \\
\text { rassment: To Who and } \\
\text { Why? }\end{array}$ & $\begin{array}{l}\text { Rape; current events; parental support for daughters } \\
\text { who are victims; minimizing victim blaming; reporting; } \\
\text { COVID-19. }\end{array}$ \\
\hline 4 & Underage Marriage & $\begin{array}{l}\text { Health implications of underage marriage; laws in } \\
\text { Egypt; marriage officials; household life in COVID- } 19 .\end{array}$ \\
\hline 5 & $\begin{array}{l}\text { Mary Asaad \& Aziza } \\
\text { Hussein }\end{array}$ & $\begin{array}{l}\text { A women's initiative to combat FGC; women's activism; } \\
\text { family planning; physical \& emotional consequences of } \\
\text { FGC; religion \& FGC. }\end{array}$ \\
\hline 6 & $\begin{array}{l}\text { What do men want from } \\
\text { women? }\end{array}$ & $\begin{array}{l}\text { sship; research on men's percep- } \\
\text { C; COVID-19 and domestic vio- } \\
\text { ative combatting DV. }\end{array}$ \\
\hline 7 & $\begin{array}{l}\text { Women threatened under } \\
\text { curfew }\end{array}$ & $\begin{array}{l}\text { DV against women during COVID-19; reporting DV } \\
\text { to police; supporting women facing DV in situations; } \\
\text { COVID-19's impacts on women generally; COVID-19 \& } \\
\text { the economy. }\end{array}$ \\
\hline 8 & FGC \& the Internet & enerational relationships; COVID-19 \& in- \\
\hline 9 & $\begin{array}{l}\text { What's the definition of a } \\
\text { man? }\end{array}$ & $\begin{array}{l}\text { A divorce after DV; raising children responsible; forgive- } \\
\text { ness for men \& men's expectations; women's views on } \\
\text { the justifiability of DV vs. men's. }\end{array}$ \\
\hline 10 & $\begin{array}{l}\text { Do women prefer kind or } \\
\text { macho (over-protective) } \\
\text { men? }\end{array}$ & $\begin{array}{l}\text { Negative effects of over-protectiveness; anecdote about } \\
\text { a marriage; spread of negative information about mar- } \\
\text { riage; shifting gender norms and women's preferences; } \\
\text { unjustifiability of any form of DV; role of doctors; re- } \\
\text { porting DV. }\end{array}$ \\
\hline
\end{tabular}

Table 35: Content of Television shows hosted on satellite channel.

\subsection{Video and Message Delivery}

Videos were displayed on a website, mshlwa7dek.org (A transliteration of "You are not alone"). 


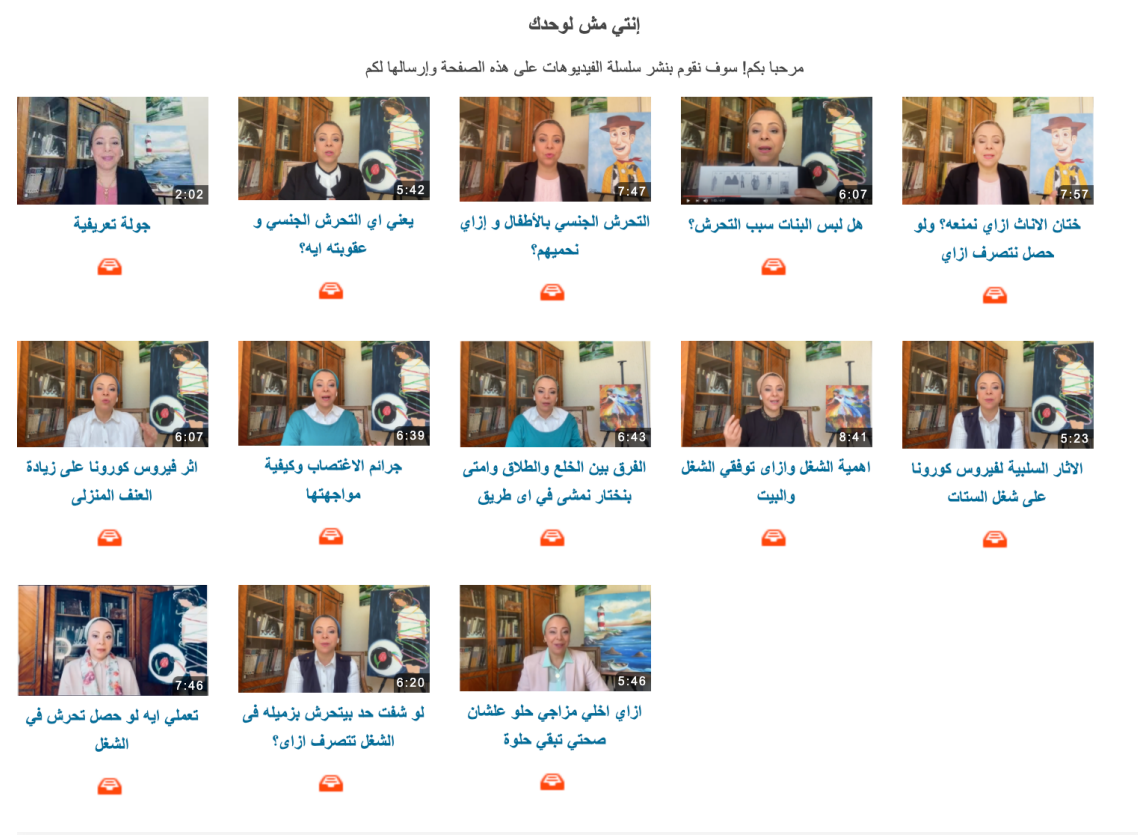

Figure 9: The home page for the website, mshlwardek.org, contained a link to each video.

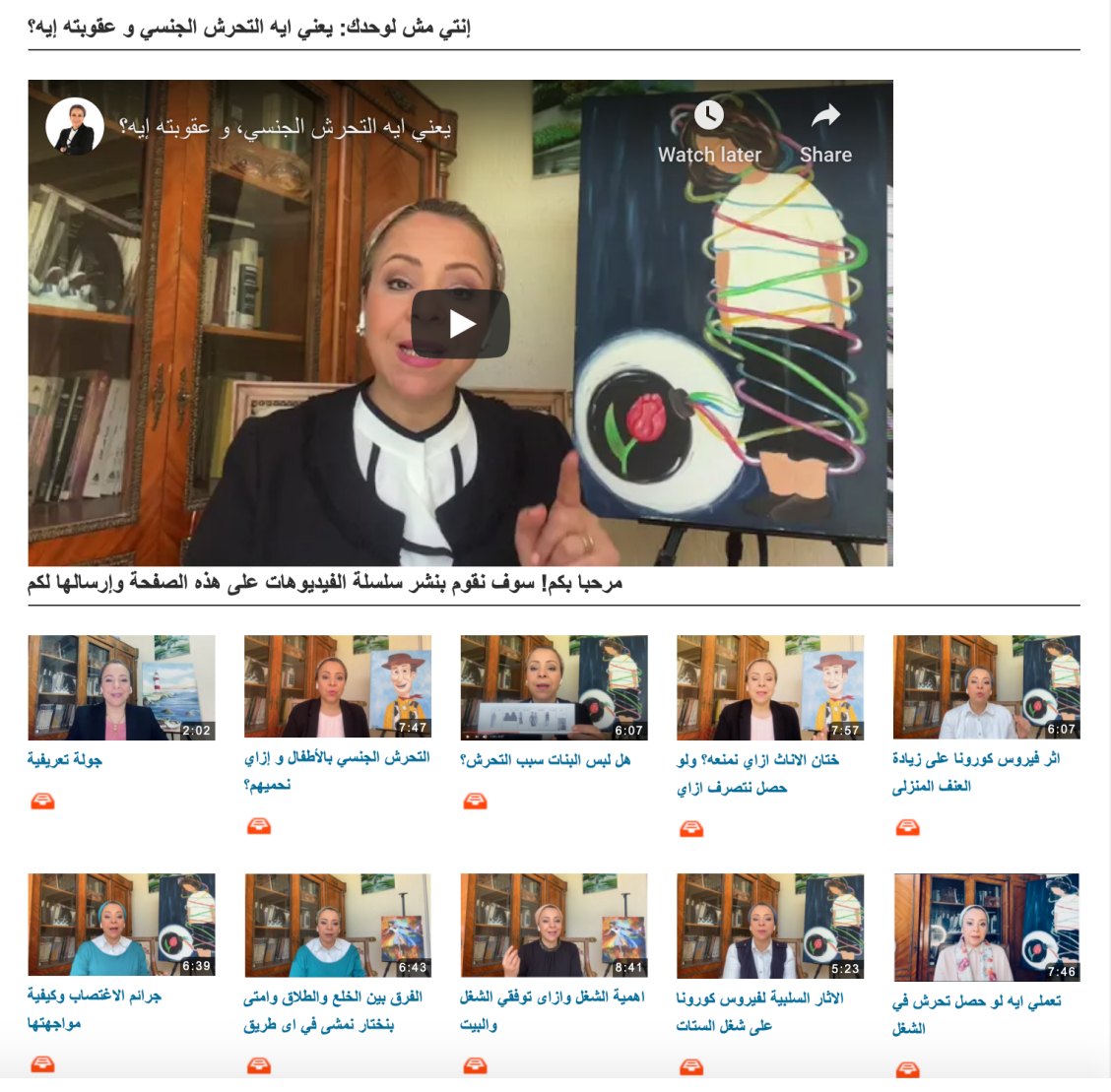

Figure 10: Each video landing page also contained a link to subsequent videos. 


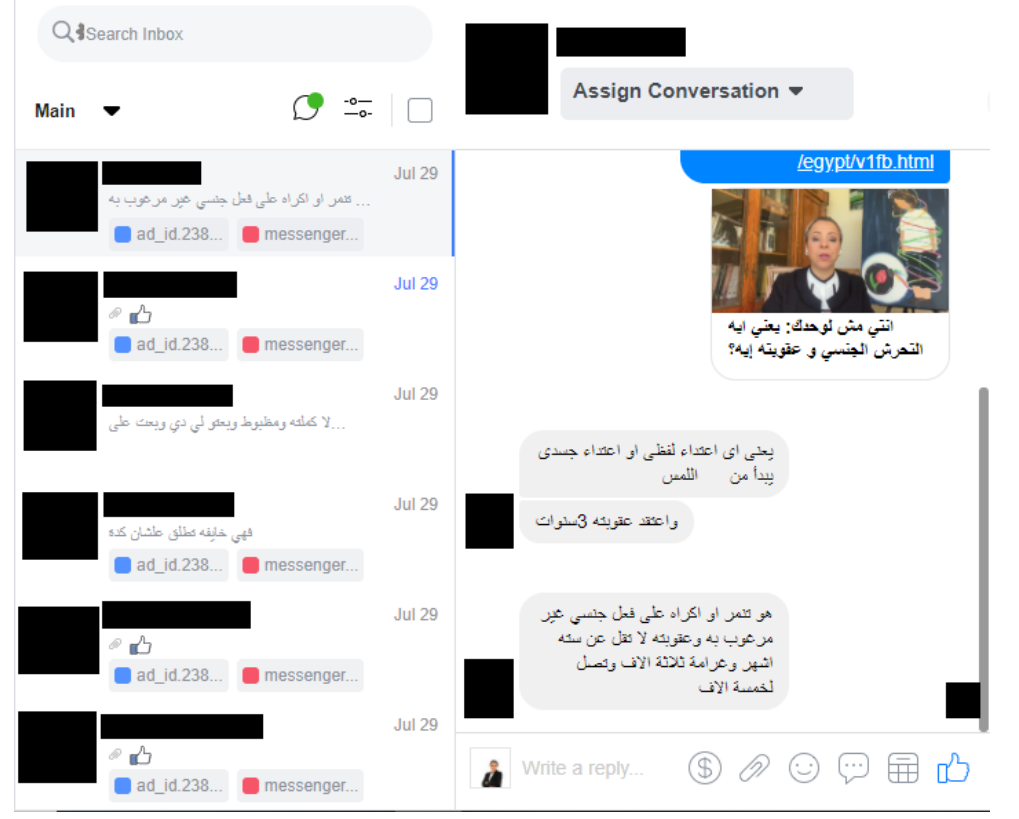

Figure 11: A video is delivered via Facebook, and a user responds with information about the definition of sexual assault.

\subsection{Map and Sample Representativeness}

See map in Figure 1.

\section{Survey Instrument}




\begin{tabular}{|c|c|c|c|}
\hline Governorate & Percent Population & Baseline Responses & Percent Baseline \\
\hline Cairo & 0.105 & 3338 & 0.582 \\
Alexandria & 0.055 & 733 & 0.128 \\
Giza & 0.086 & 269 & 0.047 \\
Asyut & 0.048 & 220 & 0.038 \\
Dakahlia & 0.068 & 180 & 0.031 \\
Gharbia & 0.054 & 152 & 0.026 \\
Sohag & 0.052 & 137 & 0.024 \\
Minya & 0.059 & 109 & 0.019 \\
Sharqia & 0.074 & 109 & 0.019 \\
Minya & 0.059 & 66 & 0.011 \\
Faiyum & 0.036 & 65 & 0.011 \\
Beheira & 0.066 & 58 & 0.01 \\
Luxor & 0.013 & 56 & 0.01 \\
Beni Suef & 0.032 & 45 & 0.008 \\
Ismailia & 0.013 & 41 & 0.007 \\
Suez & 0.007 & 38 & 0.007 \\
Port Said & 0.008 & 34 & 0.006 \\
Qena & 0.035 & 27 & 0.005 \\
Monufia & 0.045 & 21 & 0.004 \\
Aswan & 0.016 & 20 & 0.003 \\
Red Sea & 0.004 & 13 & 0.002 \\
Kafr El Sheikh & 0.036 & 4 & 0.001 \\
New Valley & 0.003 & NA & 0.001 \\
Matrouh & $\mathrm{NA}$ & $\mathrm{NA}$ & 0 \\
Damietta & 0.015 & 5740 & $\mathrm{NA}$ \\
North Sinai & 0.005 & & $\mathrm{NA}$ \\
South Sinai & 0.002 & 1 & \\
\hline Total & & & \\
\hline
\end{tabular}

Table 36: Baseline Responses vs. Population Estimates 


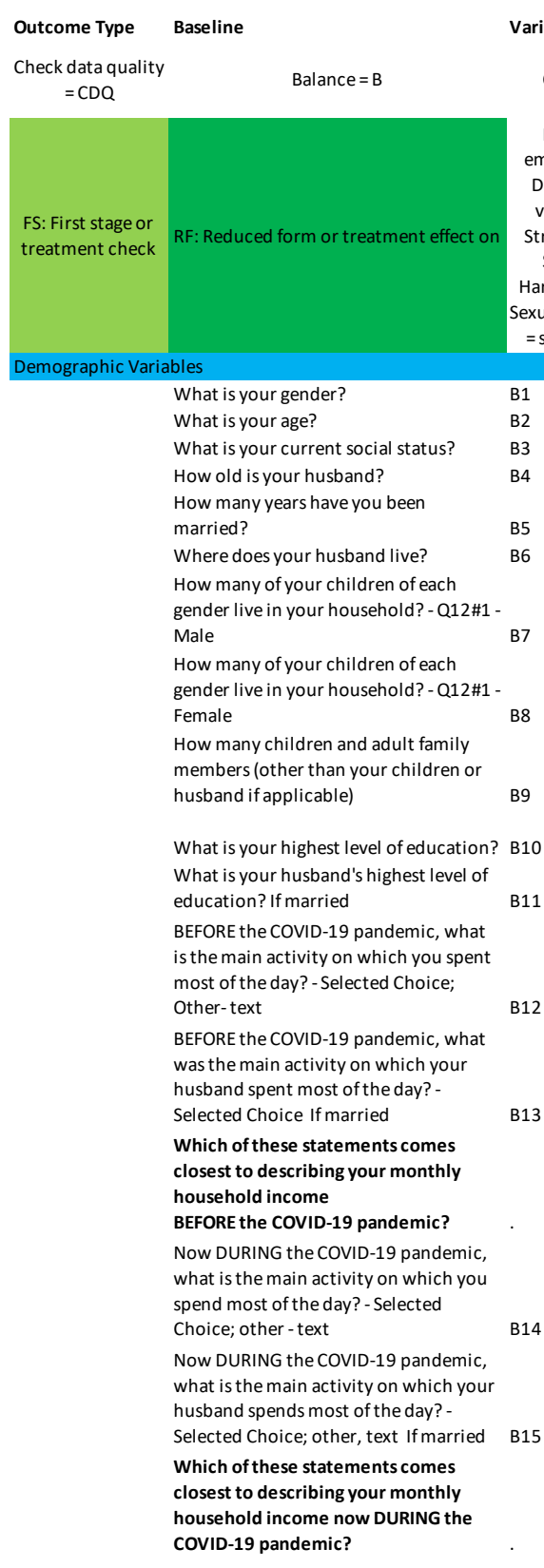

Variable name Endline

Control $=\mathrm{C}$

$\mathrm{FE}=$ Female

empowerment;

$\mathrm{DV}=$ Domestic

violence; $\mathrm{SV}=$

Street violence;

$\mathrm{SH}=$ Sexual

Harassment; $\mathrm{SV}=$

= sexual assault

\section{What is your gender?}

ariable name coding

Treatment
effect on $=\mathrm{T}$
Role Baseline Role Endline Partner's show

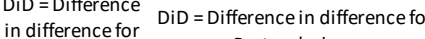

A: Attitude or Perception; FO = Future Outlook; HB = A thetical behavior; $K=$ Knowledge; $(R=$ Reporting Behavior); RP = Revealed preference

Continuous
Ix each status
Continuous
Continuous
Ix husband in household

Continuous

Continuous

Continuous

Continuous/Dummy

Continuous / Dummy

Ix based home / COVID-19 moved B, C, HEs based home / COVID-19 moved her to household

Ix based home / COVID-19 moved B, C, HEs based home / COVID-19 moved husband to household

Ix based home / COVID-19 moved B, C, HEs based home / COVID-19 moved her to household

Ix based home / COVID-19 moved B, C, HEs based home / COVID-19 moved husband to household 
Do you usually watch TV at the

following times of day?

Do you have any of the following

television options?

B18

Of the following television channels, please select the UP TO THREE you view most frequently: - Selected Choice; What type of UP TO THREE of the following television shows do you watch the most?

Which show, if any, do you usually watch on Saturday evening? - Selected Choice; Text

In the past two months, how frequently have you seen TV shows on women's legal rights?

How many hours on a typical day do

you spend on social media platforms?

(Facebook, Twitter, WhatsApp, etc.) B30

Which social media and text messagin

services do you actively use (at leas

once a day)? Indicate all that you

actively use. - Selected Choice B3

Which social media and text messaging

services do you actively use (at least

once a day)? Indicate all that you

Do you usually watch TV at the following times of day? E17

Of the following television channels, please select the UP TO THREE you view most frequently: - Selected

Choice; Text

What type of UP TO THREE of the following television shows do you watch the most?

Which television show, if any, have you watched on Saturday evening the past two months? - Selected Choice; Text

Did you watch the show Hekayat Partner?

Ix Morning; Afternoon, evening B, C

FS: Ix Evening

Have you heard of the television show Hekayat Partner?

How did you hear of it?

In the past two months, did you get a reminder over

WhatsApp to watch the television show Hekayat

Partner?

Approximately, how many episodes of the show did you

watch?

Can you briefly describe the content of an episode or

episodes that you watched?

Can you briefly tell us which topics of the show you

liked the most?

Ix TV options of Partner's show B, C, DiD via LASSO

In the past two months, how frequently haveyou seen

TV shows on women's empowerment and support? E29

$B, C$, DiD via LASSO
Ix TV channels of Partner's show B, C, DiD via LASSC FS: Ix TV channels of Partner's show

Ix Partner's show type

B, C, DiD via LASSC FS: Ix Partner's show type

21 (slightly diffe Ix Main shows, T Ix watched Partr B, C, DiD via LASSC FS: Ix watched Partner's show 22 Ix watched Partner's show Ix watched Partner's show

\section{Ix heard Partner's show}

Ix heard via WhatsApp

FS: Ix heard Partner's show

FS: Ix heard via WhatsApp

Ix got WhatsApp reminder about show

FS: Ix goFS: WhatsApp reminder abouFS: show

Continuous

FS: Continuous

Ix content accurate

FS: Ix content accurate

Ix topic accurate

FS: Ix topic accurate

(n)

In the past two months, how frequently have you seen information or vic women's issues, including domestic violence and legal rights, on Facebook, Instagram, Twitter, or Youtube? In the past two months, how frequently have you received information or videos on women's issues, including domestic violence and legal rights, through WhatsApp?
Over the past two months, how frequently have you

and support on Facebook, Instagram, Twitter, or

Youtube?

E33 (slightly diffe Continuous / Ix at al

$B, C$

FS: Continuous / Ix at al

Over the past two months, how frequently have you

seen information or videos on women's empowerm

and support on WhatsApp?
$B, C$ 
Over the past two months, did you receive any videos on

empowerment in Egypt?

WhatsApp or Faceboo

E35

E36
E37

how many videos did you watch?

Can you briefly describe the content of avid

watched? - Selected Choice; Description - text

Can you briefly tell us which topics of the videos you

liked the most? - Selected Choice - description - text

Please tell us about any additional topics that you

would like to know about: - Selected Choice description - text

\section{E38}

E39

E40

Husbands should usually have final say in all decisions

concerning the family.

Husbands should usually have final say
in all decisions concerning the family.

If a family has to choose which child

should the

education of women.

If possible, husbands should provide the

household income, and women should

stay at home taking care of the children,

elderly, and housework.

Husbands are sometimes justified in

yelling at their wives (e.g., when the

wife disobeys them).

Husbands are sometimes justified in

hitting or beating their wives (e.g.

when they are under immense financial

.

say with their husbands in all decisions

concerning the family.

In the future, men and women in Egypt

will have more equal legal rights, access

to education, and economic

If possible, husbands should provide the household income, and women stay at home taking care of the children, elderly, and housework

In the future, women will have an equal say with their husbands in all decisions concerning the family.

In the future, men and women in Egypt will have more equal legal rights, access to education, and economic opportunities.

gain

By working outside the household, a woman can gain

independence that might be beneficial to the

relationship with her husband and children.

If a male colleague al ways comments on the looks of a

female colleague even without being explicitly sexual or

making her uncomfortable, it is sexual harassment.

If you see a man sexually harrassing a woman in your

workplace, you should interfere to support the woman. E50

When women wear socially inappropriate clothing or

do not wear the hijab, men are sometimes justified in

harassing them on the street.

Others should interfere if they see a man hitting a

woman on the street, even if it turns out the man and

the woman are married.

If you see a man sexually harassing a woman in the

street, you should interfere to support the woman.

If a daughter informs her parents she has been sexually

assaulted, they should avoid going to the authorities so

that the issue does not become public and goes away

quietly.

If a child in your family tells you that a relative you trust

very much has sexually harassed them, you should take

them seriously.
WhatsApp or Facebook related to women's

$\begin{array}{ll}\text { Ix received video } & \text { FS: |x received video } \\ \text { Ix watched video } & \text { FS: Ix watched video } \\ \text { Continuous / Ix at all } & \text { FS: Continuous / Ix at all } \\ \text { Ix content accurate } & \text { FS: |x content accurate } \\ \text { Ix topic accurate } & \text { FS: |x topic accurate } \\ \text { Ix topic not covered } & \text { FS: |x topic not covered??? }\end{array}$

Continuous / I x weak or strong ag B, C

RF: Continuous / I w weak or strong against

Continuous / I w weak or strong ag B, C 
The verbal harassment that women usually suffer in the street is a form of sexual harassment, and has legal 
Suppose that a friend tells you that she has been affected by domestic violence would you be to recommend her to: Contact an organization that supports and advises women affected by

Suppose that a friend tells you that she has been affected by domestic violence and asks you for your advice How likely would you be to recommend her to: Contact an organization that supports and advises women affected by domestic violence?

ells you that she has been affected

Suppose that a lend tells you that she has been affected by sexual assault or harassment and asks you for your Tak to her family members of someone she trusts to

assist her?

Suppose that a friend tells you that she has been affect

by sexual assault or harassment and asks you for your advice. How likely would you be to recommend her: Report to designated authorities?

Suppose that a friend tells you that she has been affected by sexual assault or harassment and asksyou for your advice. How likely would you be to recommend her to: Lok for online resources for women affected by sexual assault or harassment?

Suppose that a friend tells you that she has been affected by sexual assault or harassment and asks you for your Contact an organization that supports and advises women affected by sexual assault or harassment?

SA or SH, K

Which online resources do you know for women affected by domestic violence? List up to five options

$\begin{aligned} \text { DV or SA or SH, K } & \text { Selected Choice, } 1 \text { through } 5 \\ & \text { BEFORE the COVID-19 pandemic, did } \\ & \text { you ever look for or access online } \\ & \text { resources for women affected by }\end{aligned}$

$\begin{aligned} \text { DV or SA or SH, K } & \text { Selected Choice, } 1 \text { through } 5 \\ & \text { BEFORE the COVID-19 pandemic, } \\ & \text { you ever look for or access onlin } \\ & \text { resources for women affected by }\end{aligned}$

DV or SA or SH, B domestic violence?

Now DURING the COVID-19 pandemic, online resources for women affected by

domestic violence. Please select as many options as you

Please select all of the options that you know of that are available to a woman who has been affected by sexual you know of - Selected Choase select as many options as

Which online resources do you know for women affected by domestic violoyce, or who face sexual-

harassment or assault? List up to five options. - Selected

In the month BFFORE the COVID-19 pandemic, did vou

ever look for or access online resources for women

Now DURING the COVID-19 pandemic, in the past

resources for women affected by domestic violence, or

who faced sexual harassment or assault?

Which organizations do you know that support and

advise women affected by domestic violence, or who

options. - Selacted Cho assaul? ?ist up to domestic violence? List up to five

DV or SA or SH, K options. - Selected Choice, 1 through 5 B81 BEFORE the COVID-19 pandemic, did supports and advises women affected by

DV or SA or SH, B domestic violence?

In the month BEFORE the COVID-19 pandemic, did you ever contact an organization that supports and advises sexual harassment or assault?
Ix online resources, Ix contact organization

RF: Ix online resources, I contact organization
RF: Ix online resources, Ix contact organization \#valid, \#Partner's

Continuous/Ix at all

B, C

\# valid, \#Partner's

B, C

Continuous / Ix at all 
Now DURING the COVID-19 pandemic,

have you ever contacted an

rts and advises DV or SA or SH, R women affected by domestic violence? B83
Now DURING the COVID-19 pandemic, in the past

month have you ever contacted an organization that

supports and advises women affected by domestic

Donation

Continuous / Ix at all

$B, C$

RF: Continuous/Ix at all

RF: Continuous/Ix at all 